\title{
A Base Integer Programming Model and Benchmark Suite for Liner-Shipping Network Design
}

Brouer, Berit Dangaard; Alvarez, Fernando; Plum, Christian Edinger Munk; Pisinger, David; Sigurd, Mikkel M.

Published in:

Transportation Science

Link to article, DOI:

10.1287/trsc.2013.0471

Publication date:

2014

Link back to DTU Orbit

Citation (APA):

Brouer, B. D., Alvarez, F., Plum, C. E. M., Pisinger, D., \& Sigurd, M. M. (2014). A Base Integer Programming Model and Benchmark Suite for Liner-Shipping Network Design. Transportation Science, 48(2), 281-312 . https://doi.org/10.1287/trsc.2013.0471

\section{General rights}

Copyright and moral rights for the publications made accessible in the public portal are retained by the authors and/or other copyright owners and it is a condition of accessing publications that users recognise and abide by the legal requirements associated with these rights.

- Users may download and print one copy of any publication from the public portal for the purpose of private study or research.

- You may not further distribute the material or use it for any profit-making activity or commercial gain

- You may freely distribute the URL identifying the publication in the public portal 

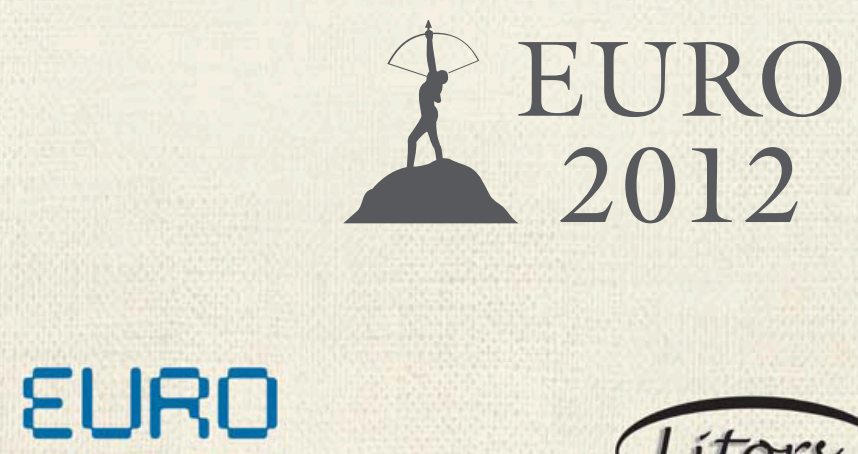

The Association of European Operational Research Societies
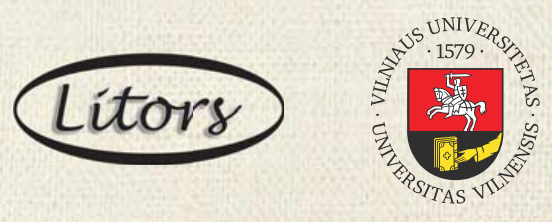

\title{
$25^{\mathrm{TH}}$ EUROPEAN CONFERENCE ON OPERATIONAL RESEARCH
}

\author{
8-11 July 2012. Vilnius, Lithuania
}




\section{CONTENTS}

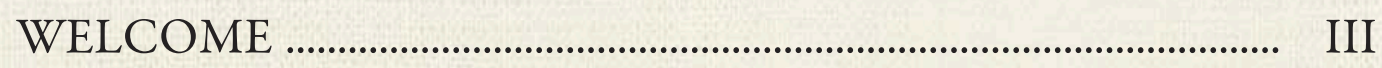

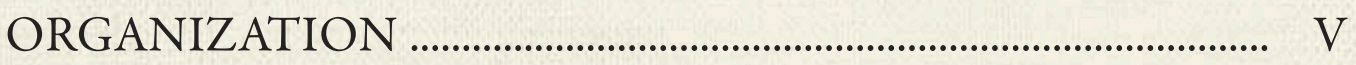

INSTITUTIONAL SUPPORT …………………….................. VI

ABOUT THE CONFERENCE _.................................................... VII

REGISTRATION ……................................................................. VIII

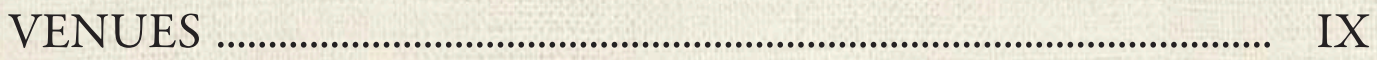

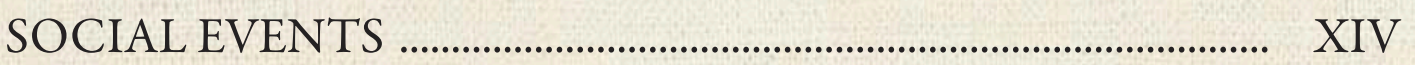

OPENING SESSION _............................................................. XVI

CLOSING SESSION _................................................................... XVII

GUIDELINES FOR SESSION CHAIRS _....................................... XVIII

GUIDELINES FOR SPEAKERS _.................................................. XVIII

GENERAL INFORMATION _.................................................... XIX

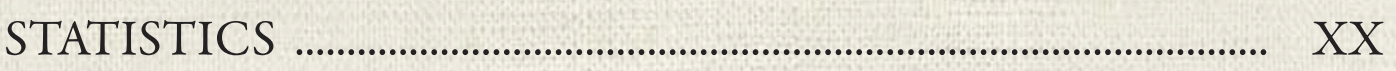

EURO AWARDS AND PRIZES _................................................. XXI

INVITED SPEAKERS _............................................................... XXIII

SPONSORS / EXHIBITORS _.................................................... XXXVI

OVERVIEW OF THE PROGRAMME .......................................... XLI

TECHNICAL SESSIONS _.......................................................... LI 


\section{$N / N$
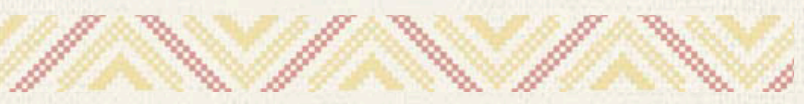 \\ $25^{\text {th }}$ European Conference on Operational Research \\ 8-11 July 2012. Vilnius, Lithuania}

\section{WELCOME}

\section{Dear participant,}

It is a great pleasure to welcome you to the 25th EURO conference in Vilnius. The conference offers you the opportunity to meet the EURO community and the many researchers coming from outside the EURO region. It also offers you an exposure to the evolution of the several areas that compose Operational Research, to keep you updated on our continuously evolving dynamic discipline. During the conference you will certainly meet old and new colleagues, exchange ideas, develop new projects. You will also feel and enjoy the special atmosphere of Vilnius and Lithuania.

The scientific and social programs are very rich and I invite you to explore the several options offered by the conference. Among the options there are a few that I wish to emphasize because of their exceptional level: the lecture of Ralph E. Gomory, who has given some of the most fundamental contributions to Operational Research, and the lecture of the Nobel prize winner Finn E. Kydland, who will link economics to our discipline. Another exceptional event that will take place during the conference is the special session dedicated to EURO and its Presidents. EURO has had 18 Presidents since its foundation in 1976. Besides awarding the Past Presidents for their contribution to EURO, in this special session Hans-Jürgen Zimmermann, the first President of EURO, will go back to the roots of EURO and will depict the evolution of the EURO community over time. I invite you also to visit the Springer stand and have a look at the first issue of the EURO Journal on Transportation and Logistics, one of the three new EURO journals.

I am confident you will find the 25 th EURO conference stimulating, rewarding and pleasant and that you will enjoy your staying in Vilnius.

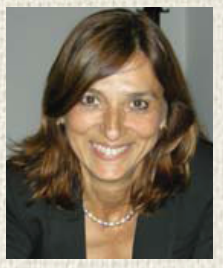

M.Grazia Speranza

President of EURO

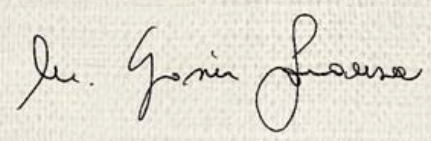




\section{Dear conference participants,}

It is a great honour and pleasure to welcome you to the 25th European Conference on Operational Research - EURO XXV in Vilnius on 8 - 11 July, 2012.

The theme of the conference is - OR Connecting Sciences. Operational Research is a multi-disciplinary field in its own right. It provides strategies and decisions for individuals as well as for institutions, taking into account the complex interactions between people and the world. By connecting to a larger set of existing and new sciences, it is our hope that $\mathrm{OR}$ can become an instrument for providing adequate solutions to new challenges in business, technology and society as whole.

EURO XXV will focus on the most relevant topics and issues in European and global science in the field of OR theory and advanced applications via our three plenaries, a set of twelve keynote and tutorial lectures, presentations by award winners and candidates for these awards as well as by invited and contributing speakers. With 524 sessions and almost 2000 presentations and more than 2100 participants from 68 countries, EURO XXV will provide a stimulating opportunity for a global interchange of ideas on all recent advances in OR.

We would like to take this opportunity to express our sincere thanks to all who have supported us in preparing this event. We are grateful to the members of the Programme Committee, who organized twenty five main areas consisting of 153 streams, and to the stream organizers, who coordinated the invited sessions and managed to attract so many researchers. We warmly thank the members of the Organising Committee and the EURO XXV Secretariat for their priceless dedication and hard work in putting everything together.

In the tradition of the EURO conferences a number of social events are scheduled, and we believe that EURO XXV will also be a special experience for all of us. Vilnius is the historical capital of Lithuania dating back to the 14 th century. The city has the most beautiful old town. It has been awarded the status of World Cultural Heritage by UNESCO and its university is one of the oldest in Eastern Europe. Vilnius is rapidly expanding as a modern European capital, so you will have the opportunity of experiencing the harmonious meeting of old and new.

We wish you all an interesting, exciting, and enjoyable time in Vilnius.

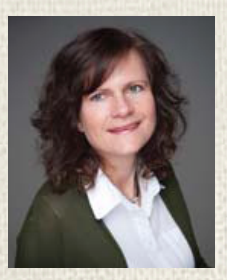

Marielle Christiansen

Chair of Programme Committee

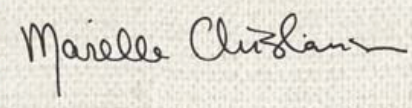

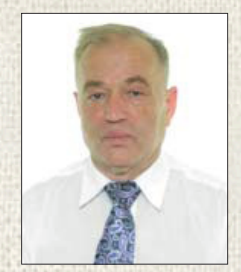

Leonidas Sakalauskas

Chair of Organising Committee

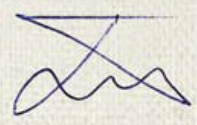




\section{ORGANIZING COMMITTEE}

\section{Leonidas Sakalauskas - Chair}

Vilnius University, Lithuania

Marielle Christiansen

Norwegian University of Science and Technology, Trondheim, Norway

\section{Saulius Preidys}

Vilnius University, Lithuania

\section{Tatjana Vilutiene}

Vilnius Gediminas Technical University, Lithuania

Gerhard Wäscher

Otto-von-Guericke University of Magdeburg, Germany

Jonas Zaptorius

Vilnius Gediminas Technical University, Lithuania

\section{PROGRAMME COMMITTEE}

\section{Marielle Christiansen - Chair}

Norwegian University of Science and Technology, Trondheim, Norway

\section{Karen Aardal}

Delft University of Technology, The Netherlands

\section{Elena Fernández}

Technical University of Catalonia, Barcelona, Spain

\section{Richard Hartl}

University of Vienna, Austria

Peter Letmathe

RWTH Aachen, Germany

\section{Silvano Martello}

University of Bologna, Italy

Vincent Mousseau

Ecole Centrale de Paris, France

\section{Mikael Rönnqvist}

Université de Laval, Québec, Canada

\section{Leonidas Sakalauskas}

Vilnius University, Lithuania

\section{Marc Sevaux}

Université de Bretagne Sud, Lorient, France

Stein W. Wallace

Lancaster University, UK

Gerhard Wäscher

Otto-von-Guericke University of Magdeburg, Germany

Gerhard-Wilhelm Weber

Middle East Technical University, Ankara, Turkey 


\section{INSTITUTIONAL SUPPORT}

\section{EURO \\ The Association of European Operational Research Societies}
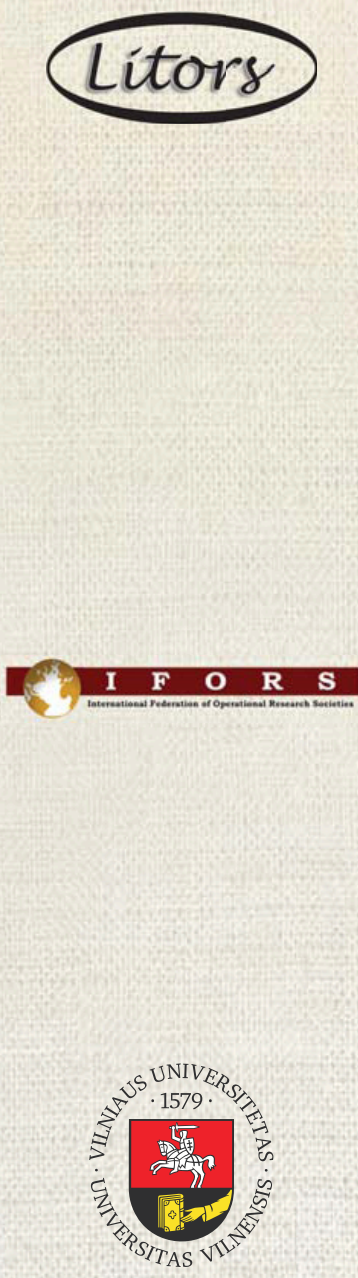

EURO is the "Association of European Operational Research Societies" within IFORS, the "International Federation of Operational Research Societies". It is a "non profit" association domiciled in Switzerland. Its affairs are regulated by a Council consisting of representatives/alternates of all its members and an Executive Committee which constitutes its board of directors. Its aim is to promote Operational Research throughout Europe. The members of EURO are normally full members of IFORS and comprise the national OR societies of countries located within or nearby (in a broad sense) Europe.

The Lithuanian Operational Research Society (LitORS) was created in 2001 and approved by EURO and IFORS in 2003. LitORS unites experts and specialists working in the field of operational research and applications, and promotes international communication and cooperation in OR science and teaching. LitORS has a rich experience of activity in a framework of EURO. The XXI Euro Summer Institute (2003), two EURO Mini Conferences (2008 and 2009) as well as several other international conferences and workshops have been organized in Lithuania. These have been attended by hundreds of participants from many countries, and they have led to the publication of many volumes or proceedings and special issues in scientific journals.

The International Federation of Operational Research Societies (IFORS) is an umbrella organization comprising the national Operations Research societies of over forty five countries from four geographical regions: Asia Pacific, Europe, North America and South America. Total membership is over 30,000 persons. IFORS' mission is to promote Operations Research as an academic discipline and a profession.

Since its establishment in the 16th century, Vilnius University, as integral part of European science and culture has embodied the concept of a classical university and the unity of studies and research. Vilnius University is an active participant in international scientific and academic activities and boasts many prominent scientists, professors and graduates. Scientific development and the expanding relations with global research centres have contributed to the variety of research and studies at Vilnius University. With the support of social partners, the university educates globally-minded specialists who successfully integrate in the modern European community. 


\section{N N N
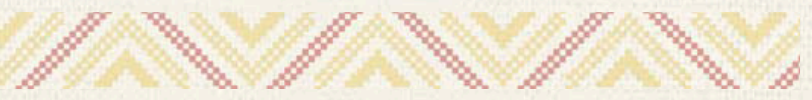 \\ $25^{\text {th }}$ European Conference on Operational Research \\ 8-11 July 2012. Vilnius, Lithuania}

\section{ABOUT THE CONFERENCE}

\section{Language}

The official language of the conference is English. No simultaneous translation will be provided.

\section{Lunches (July 9-11)}

Lunches will be served from 11:30 to 14:30 at four different venues: Radisson Blu Hotel Lietuva restaurant Riverside (ground floor); Best Western Hotel restaurant (ground floor); Cooperation college (ground floor); Restaurant "Vapiano" in the shopping mall "Europa" (ground floor).

All delegates are kindly requested to have lunch in an appointed place (those places are indicated on the lunch coupon inside your badge holder).

\section{Coffee Breaks}

Coffee, tea and other refreshments will be served during all conference hours. Please see the map for coffee break stations.

\section{Transportation}

Your badge serves as a transportation ticket for public Vilnius City Transport, buses and trolleybuses, during 8-11 July 2012. Please wear your badge while using transportation and show to inspector if requested.

PLEASE NOTE: the badge is not valid for private company transportation including buses whose numbers start with \#0, mini buses and taxis.

Conference buses will be running from Vilnius International Airport to the city center (Radisson Blu Hotel Lietuva, Best Western Hotel, Holiday Inn Hotel) accordingly to the arrivals.

Price per transfer: 10 Euro $(€)$.

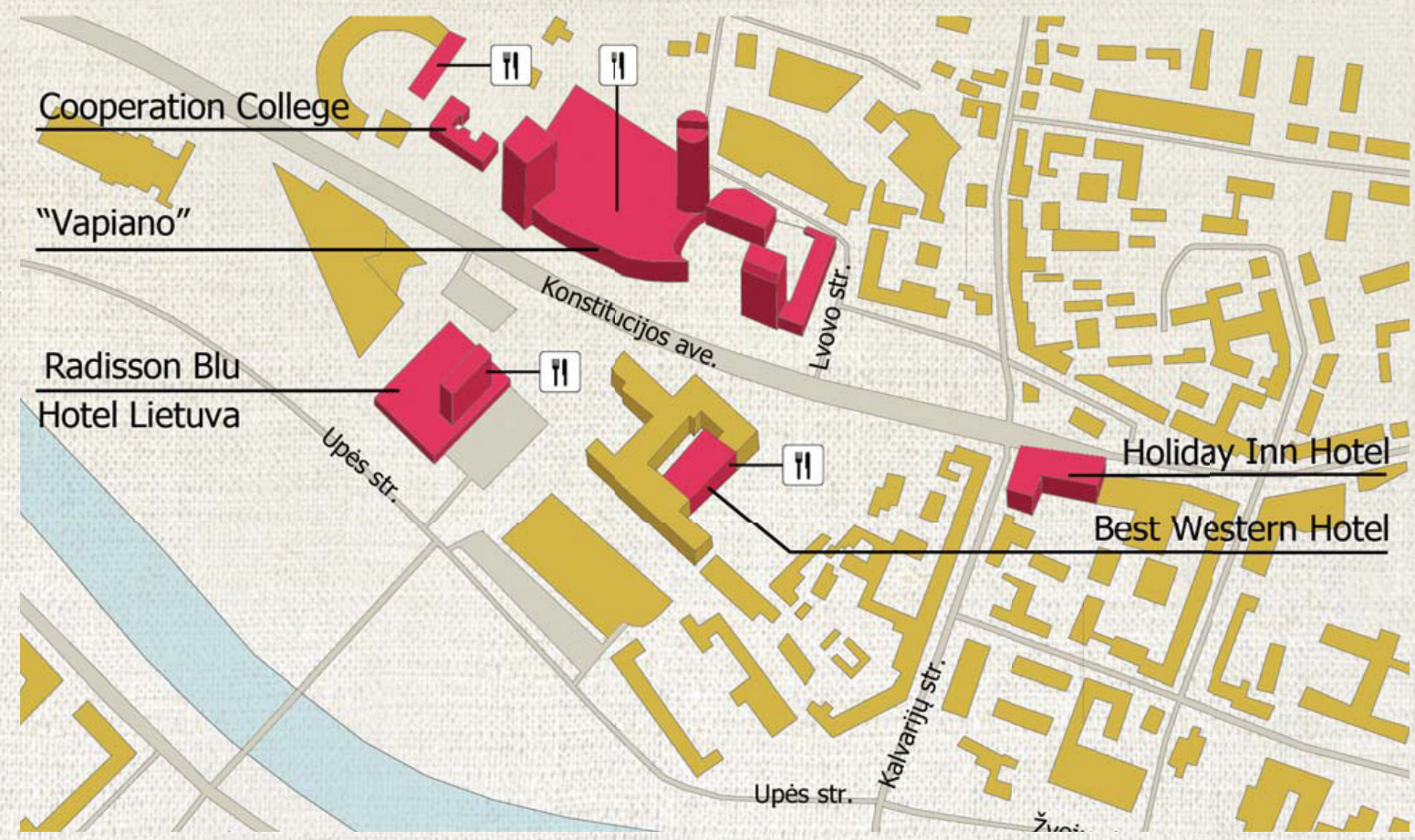




\section{REGISTRATION}

\section{Registration Desks}

8 July: The registration desk will be located in the Lithuanian National Opera and Ballet Theatre.

9-11 July: The registration desk will be located in the Conference Center of Radisson Blu Hotel Lietuva.

Opening Hours of Registration Desks

- 8 July (Sunday) 08:00-19:00

- 9 July (Monday) 08:00-17:30

- 10 July (Tuesday) 08:00-17:30

- 11 July (Wednesday) 08:00-18:40

\section{Registration Fee, Badges}

The regular/student registration fee includes:

- Participation in all sessions, and access to the exhibition area

- Conference materials (Bag, Conference Programme, Pocket Programme)

- Participation in the Welcome Reception (8 July)

- Participation in the Vilnius City Reception (9 July)

- Participation in the Farewell Party (11 July)

- Coffee breaks and lunches (9-11 July)

- Public transportation (8-11 July)

The registration fee for accompanying persons includes:

- Participation in the Welcome Reception, the Vilnius City Reception and the Farewell Party

- Pocket Programme

- Lunches (9-11 July)

- Vilnius City Tour

- Public transportation (8-11 July)

Badges are colour-coded as follows:

Organizing/Programme Committee

Exhibitor

Participant

Volunteer

Accompanying Person 


\section{VENUES}

The following five venues will be used for the conference:

- Radisson Blu Hotel Lietuva (Address: Konstitucijos ave. 20)

- Cooperation College (Address: Konstitucijos ave. 11)

- Best Western Hotel (Address: Konstitucijos ave. 14)

- Holiday Inn Hotel (Address: Šeimyniškių str. 1)

- Lithuanian National Opera and Ballet Theatre (Address: A. Vienuolio str. 1)

Stairs

| Elevator

D. Coffee Break area

溶 Toilet

II Lunch area

H Help Desk

R Registration

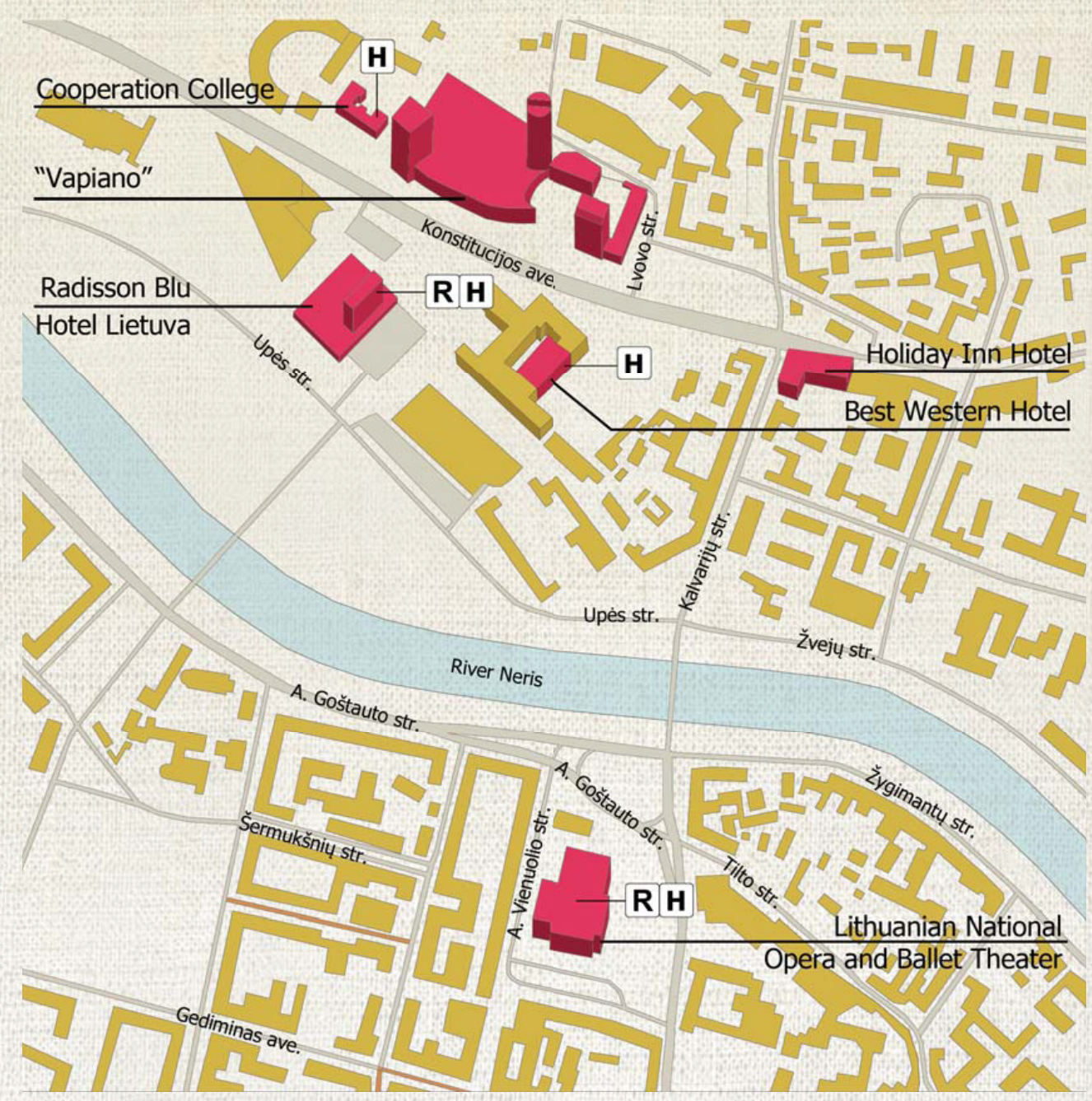


RADISSON BLU HOTEL LIETUVA (Address: Konstitucijos ave. 20)
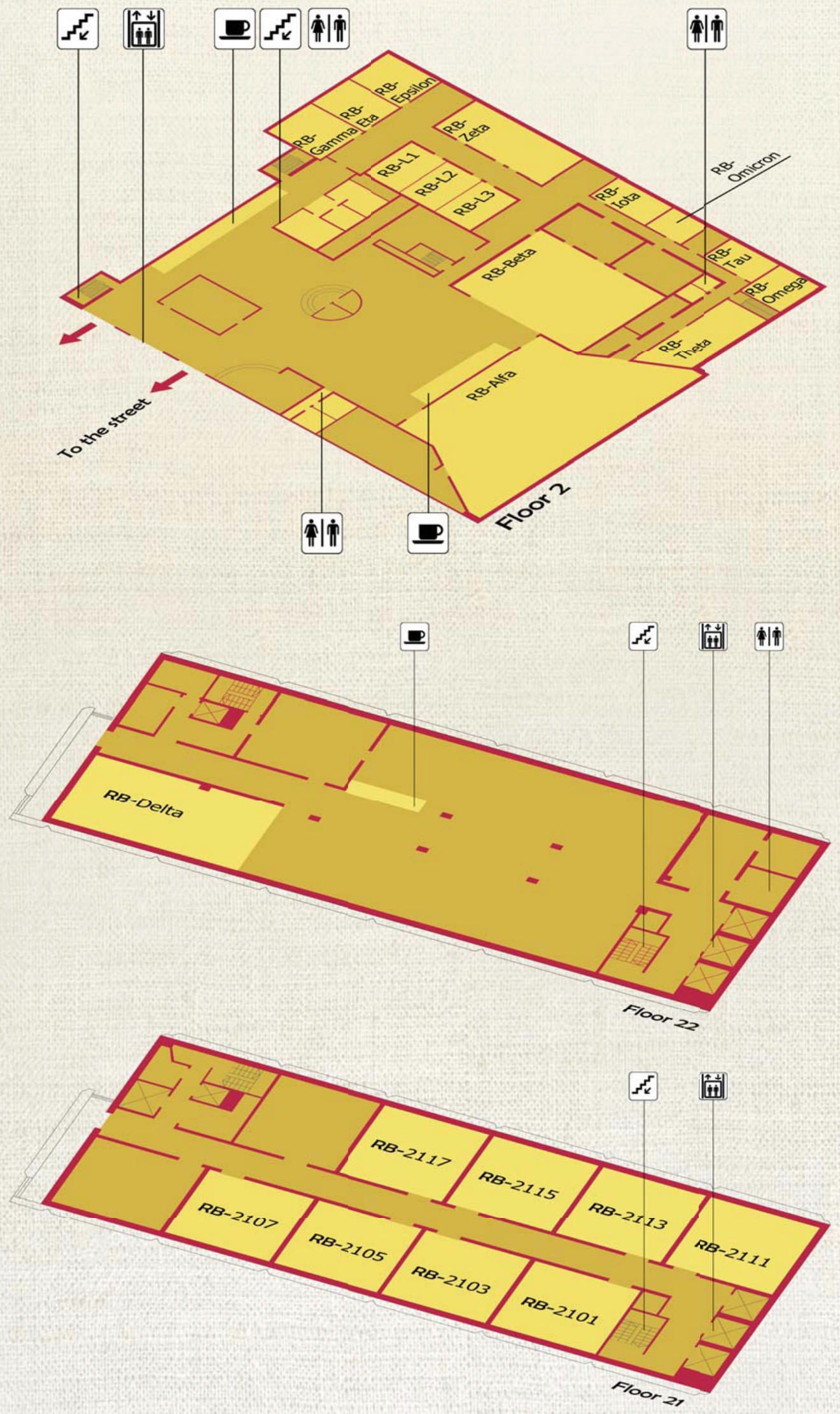


\section{W}

COOPERATION COLLEGE (Address: Konstitucijos ave. 11)

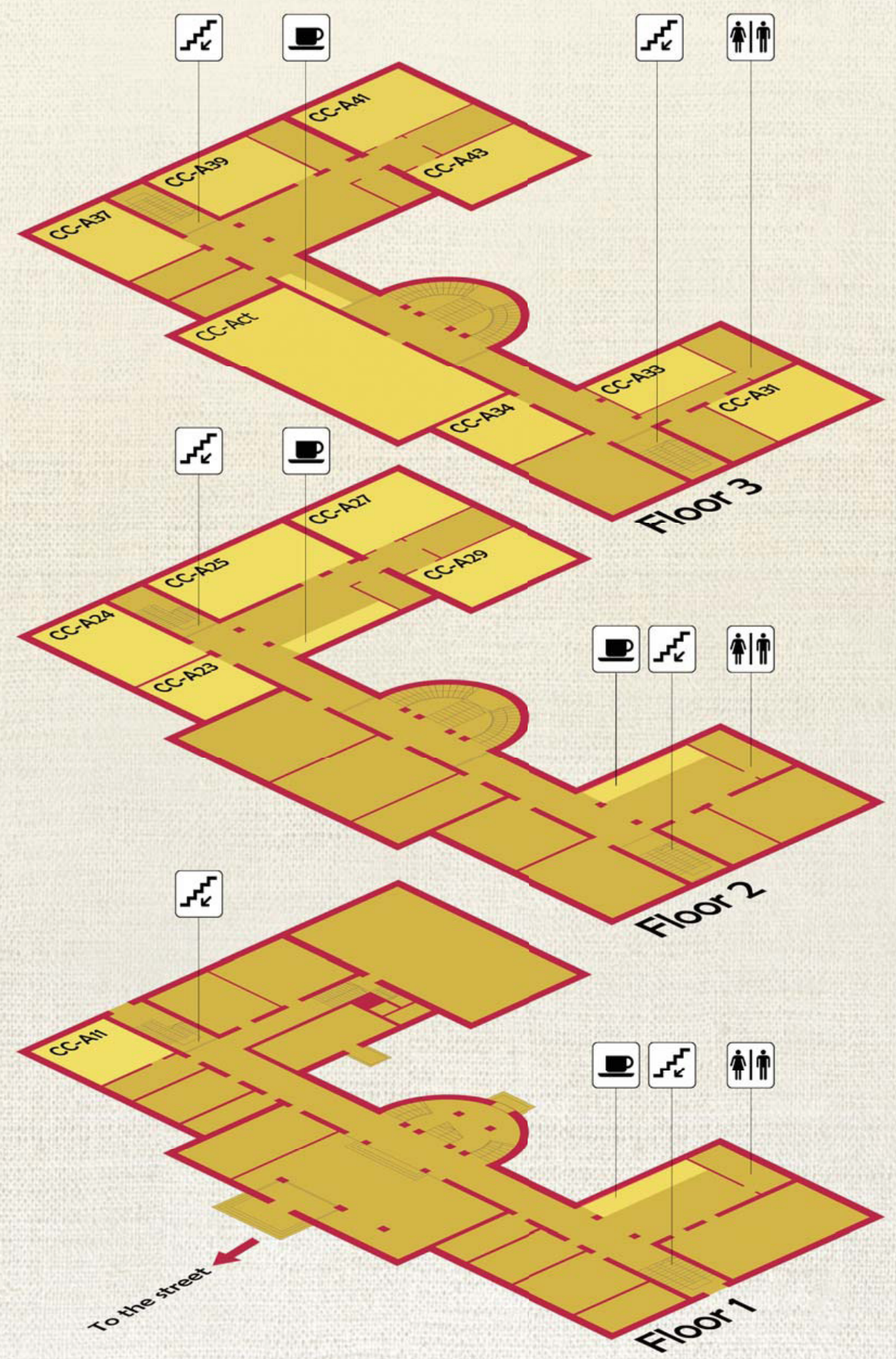




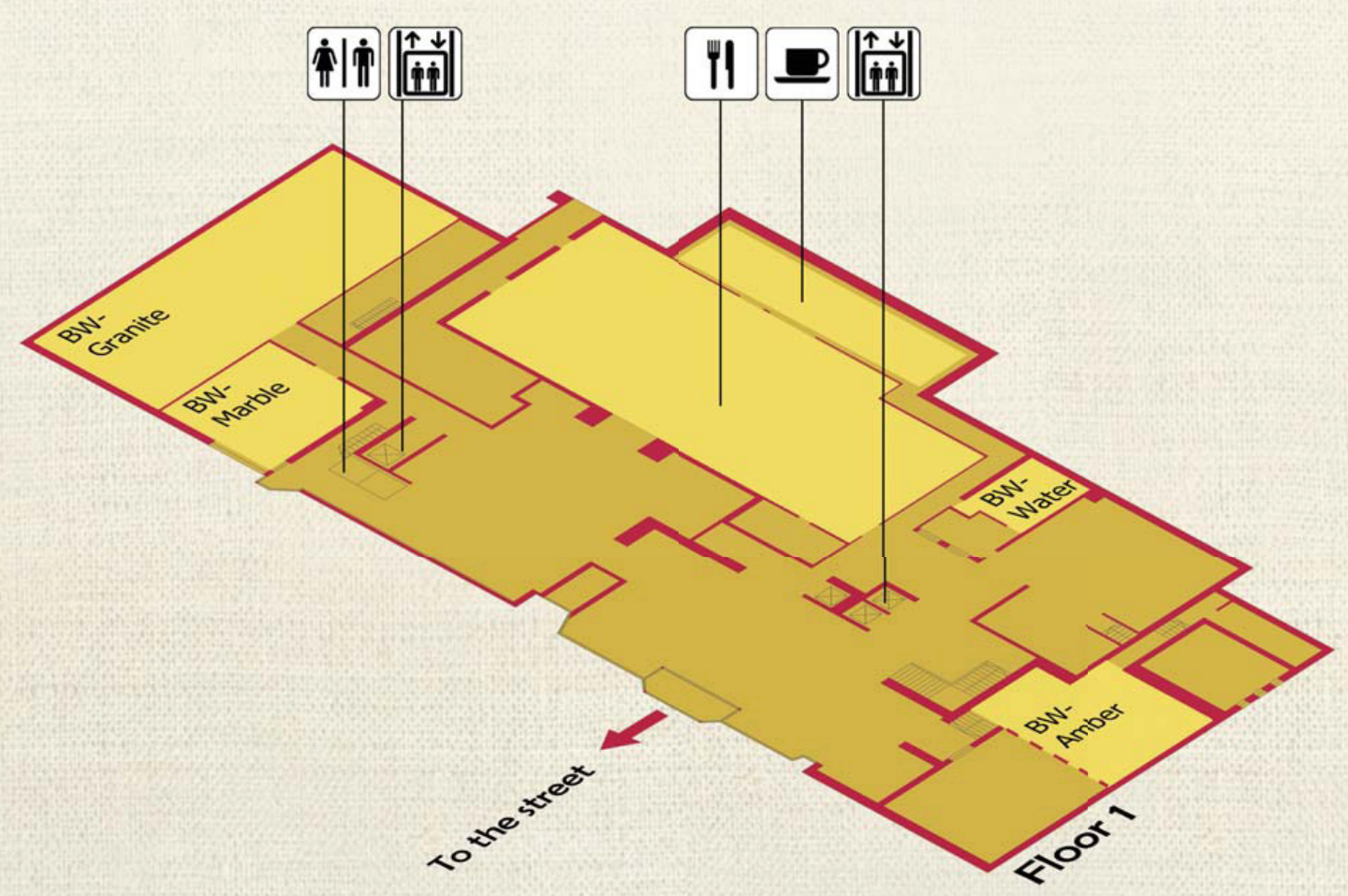


HOLIDAY INN HOTEL (Address: Šeimyniškių str. 1)

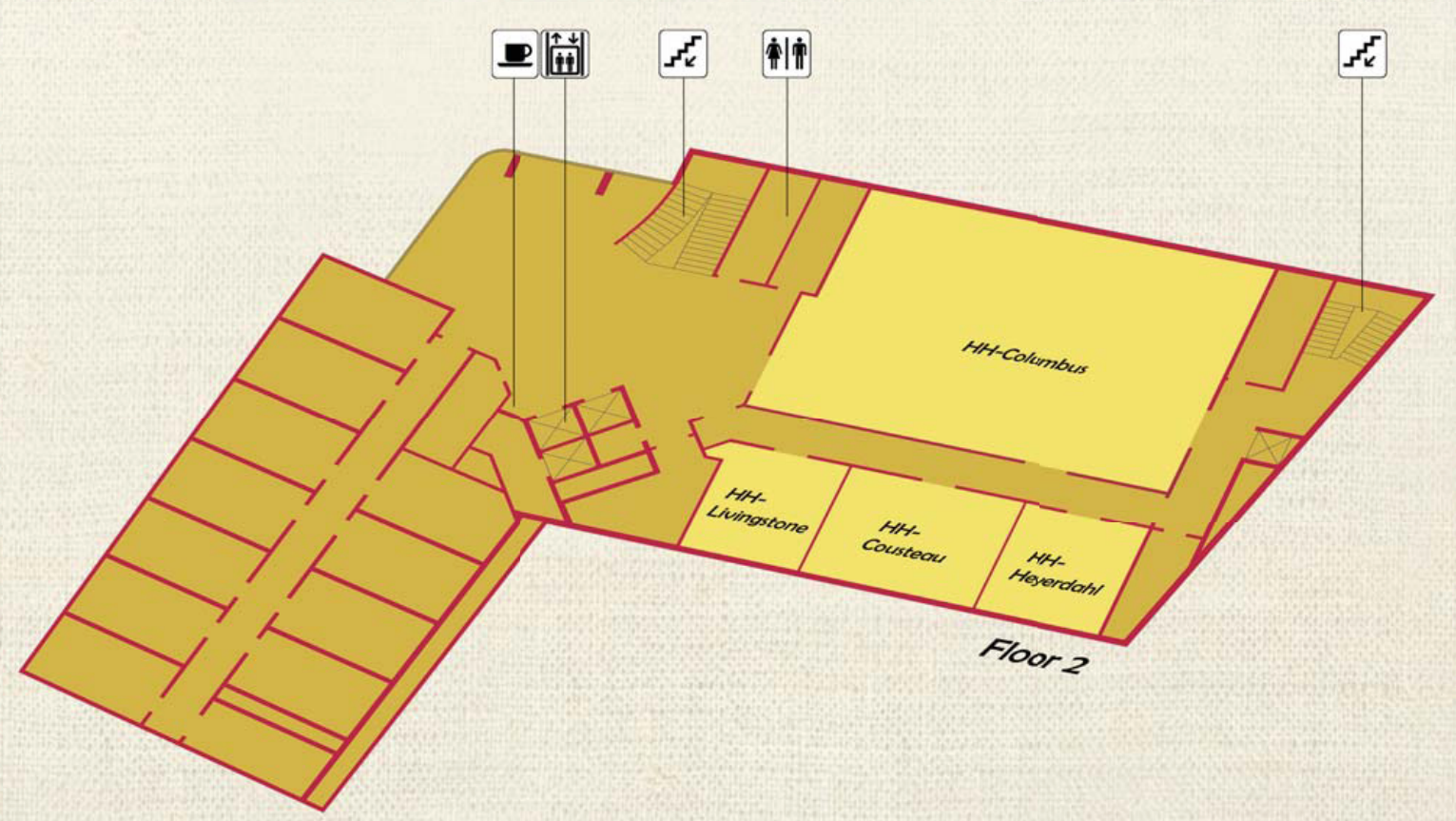




\section{SOCIAL EVENTS}

\section{Opening Session and Welcome Reception}

Date: 8 July 2012

Time: 16:00-21:00

Venue: The Lithuanian National Opera and Ballet Theatre

Address: A. Vienuolio str. 1, Vilnius

After the Opening Session at the Lithuanian National Opera and Ballet Theatre we will invite you to the Welcome Reception. The Welcome Reception with delicious snacks and refreshing drinks will set everyone for a pleasant evening. It will be the perfect opportunity to catch up with old colleagues and meet new ones.

Free of charge for all participants and accompanying persons. Please wear your badge.

\section{Vilnius City Reception}

Date: 9 July 2012

Time: $18: 30-20: 00$

Venue: Lithuanian National Opera and Ballet Theatre

Address: A. Vienuolio str. 1, Vilnius
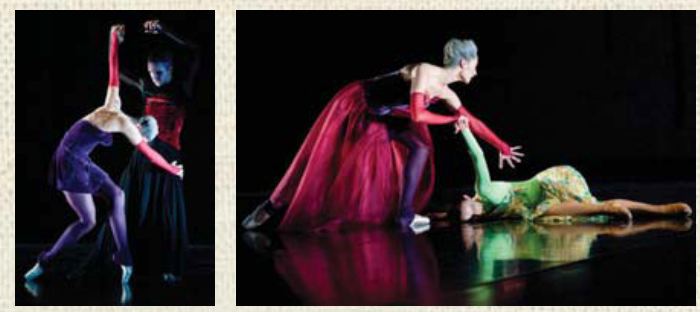

We invite you for a glass of wine and live performance by the Vilnius Ballet Theatre. Since 1980, the Vilnius Ballet Theatre has performed in the greatest theatres, creating a tradition of passion and innovation that touches the soul of ballet lovers. The Vilnius Ballet Theatre will introduce you to the most captivating and exciting ballets - from classic ballets to a more contemporary repertoire. You will be surprised by the view!

Free of charge for all participants and accompanying persons. Please wear your badge.

\section{Gala Dinner}

Date: 10 July 2012

Time: 19:00-23:00

Venue: Vilnius Picture Gallery courtyard

Address: Didžioji 4, Vilnius

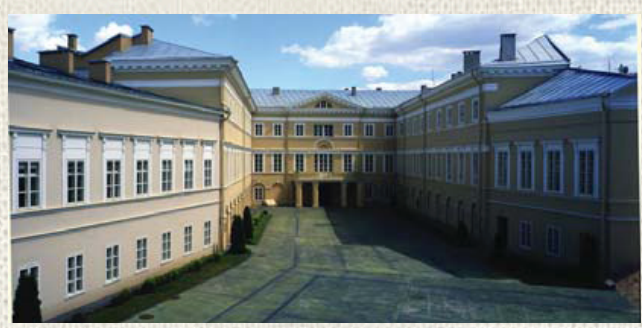

Located in the very heart of the historic Old Town, the Vilnius Picture Gallery offers facilities for cultural events. The Gala Dinner will wrap up with a fun-filled evening of music by a top Vilnius house band who will continue to provide a live and interactive party atmosphere.

Entrance with the tickets. Gala Dinner ticket is valid for one person only. 


\section{N
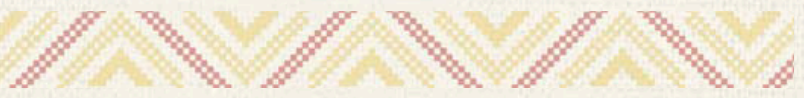 \\ $25^{\text {th }}$ European Conference on Operational Research \\ 8-11 July 2012. Vilnius, Lithuania}

\section{Farewell Party}

Date: 11 July 2012

Time: 19:15-21:00

Venue: Vilnius University (Grand courtyard)

Address: Vilnius University str. 5, Vilnius

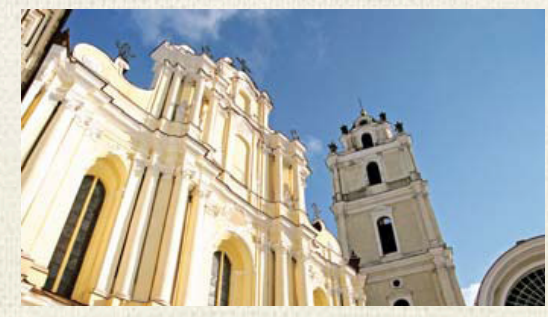

At the end of three days of sharing ideas, discussions will continue during the farewell party in the University of Vilnius. The University of Vilnius, one of the oldest and most famous establishments of higher education in Eastern and Central Europe, was founded in 1579. Functioning for a long time as the only school of higher learning in Lithuania, it was a preserver of cultural and scientific traditions, and has played a significant part in the cultural life not only of Lithuania, but the neighboring countries as well. The University is a unique witness to the history of the Lithuanian state.

Will be served delicious snacks and drinks, and to top it off, all conference guests, speakers and partners can enjoy the evening together.

Free of charge for all participants and accompanying persons. Please wear your badge.

\section{Excursions}

We are offering you a unique opportunity to explore the beauty, legends and architecture of Vilnius by taking the Vilnius City Tour or Vilnius By Night Tour. See the magnificent Castle of Trakai. Find out how Lithuania looked 100 years ago on a tour to Openair Folk Life Museum of Rumšiškès or see the European Center and Park, the leading tour to the open air contemporary art museum devoted to the center of Europe. Visit the second largest city in Lithuania Kaunas.

You are welcome to visit our Help Desk during the conference, where you can arrange tours.

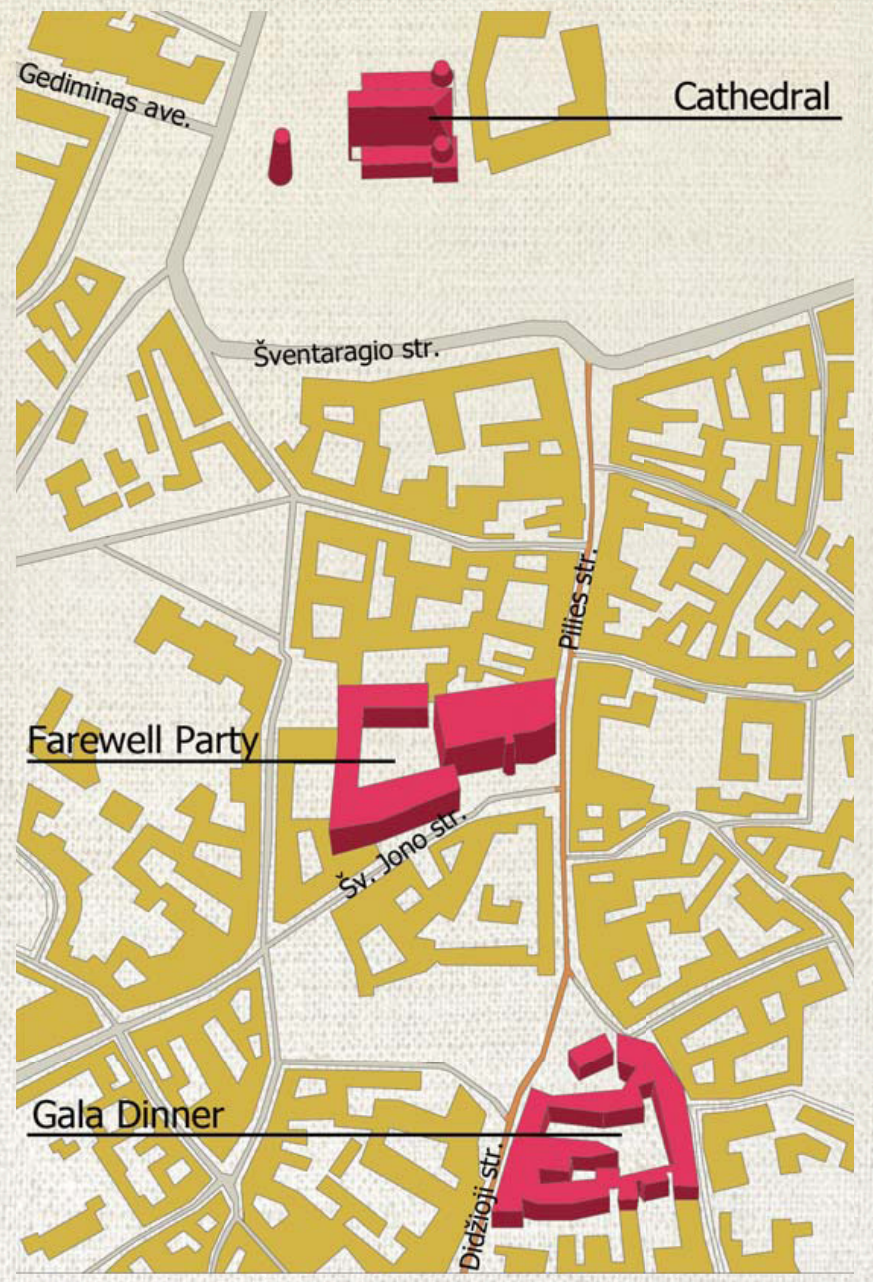




\section{OPENING SESSION}

8 July (Sunday) 16:00 - 18:00

Lithuanian Opera and Ballet Theatre (Address: A. Vienuolio str. 1)

Chair: Marielle Christiansen, Chair of the Programme Committee

\section{Welcome addresses}

- M. Grazia Speranza, President of EURO

- Leonidas Sakalauskas, President of LitORS

- Gintaras Steponavičius, Minister of Education and Science of the Republic of Lithuania

\section{Awards}

- Announcement of the winner of the EURO Distinguished Service Award. Alexis Tsoukiás (Chair)

- Announcement of the winner of the EURO Gold Medal. Rüdiger Schultz (Jury Member)

\section{Plenary presentation}

- The Laureate of the EURO Gold Medal

\section{Latest information \& special remarks}

- Marielle Christiansen, Chair of the Programme Committee

- Leonidas Sakalauskas, Chair of the Organizing Committee 


\section{CLOSING SESSION}

11 July (Wednesday) 17:40 - 18:40

Radisson Blu Hotel Lietuva, Alfa Hall (Address: Konstitucijos ave. 20)

Chair: M. Grazia Speranza, President of EURO

\section{Awards}

- Announcement of the winner of the EURO Excellence in Practice Award 2012 Michel Bierlaire (Chair)

- Announcement of the winner of the EURO Doctoral Dissertation Award Jacques Teghem (Chair)

- Announcements of the winners of the EURO Best EJOR Paper Award 2012 David Pisinger (Chair)

- Announcements of the winners of the ROADEF/EURO Challenge 2012 Christian Artigues (Chair)

\section{Announcements}

- Announcements of the special journal issues

\section{Calls}

- EURO-INFORMS Joint International Meeting, Rome 2013 Paolo Dell'Olmo (Italy), Chair of the Organizing Committee

- IFORS XX, Barcelona 2014

Elena Fernández (Spain), Chair of the Organizing Committee

\section{Farewell Addresses}

- Marielle Christiansen, Chair of the Programme Committee

- Gerhard Wäscher, President-Elect of EURO

- Leondidas Sakalauskas, Chair of the Organizing Committee 


\section{GUIDELINES FOR SESSION CHAIRS}

The role of the Chair is to coordinate and ensure the smooth running of the session. The Chair:

- should be in the lecture room 15 minutes before the beginning of the session;

- contacts the speakers before the session, to verify who will present and to preempt any technical problems;

- each session lasts 90 minutes, with 22 minutes allotted to each presentation including questions;

- introduces the speaker and the title of each presentation. Should take care of a laptop on which the presentations will be uploaded: a laptop of a speaker in the session, or of himself/herself (or, otherwise, of the organizers via the student volunteer assisting the session);

- ensures that presentations are made in the order shown in the program, to allow participants to switch between sessions. If a speaker cancels or does not attend, the original time schedule should be adhered to rather than sliding every talk forward;

- completes the session attendance form (forms will be in the room);

- when appropriate, produces visual warnings to the speaker on how many minutes (e.g., 5, 2) are left, using simple gestures or prepared cards;

- manages the questions of the audience, asks questions him/herself and thanks the speakers.

\section{GUIDELINES FOR SPEAKERS}

\section{Audio-Visual services}

All session rooms will be equipped with DLP/LCD video projectors. Laptops will be available only in: Opera Theatre, RB-Alfa, RB-Beta, RB-Zeta, RB-Theta, HH-Columbus, BW-Granite, CC-A24, CC-A25, CC-A27, CC-A29, CC-A37, CC-A41, and CC-A43. Speakers should have their presentation ready on USB disc to be used in previously named rooms.

Laptops WILL NOT BE AVAILABLE in: RB-Lambda1, RB-Lambda2, RB-Lambda3, RB-Gamma, RB-Eta, RB-Epsilon, RB-Iota, RB-Omicron, RB-Tau, RB-Omega, RB-2101, RB-2103, RB-2105, RB-2107, RB-2111, RB-2113, RB-2115, RB-2117, RB-Delta, CC-A11, CC-A23, CC-A31, CC-A33, CC-A34, CC-Act hall, HH-Cousteau, HH-Livingstone, HH-Heyerdahl, Bw-Amber, BW-Marble and BW-Water. Speakers should bring their own laptop computers in previously named rooms or session chairs are asked to make their laptop available for other speakers.

Please follow these guidelines to ensure a successful presentation:

- Bring your presentation on a USB data stick (USB pen).

- Arrive at your session at least 15 minutes before it begins. All presenters in a session should set up and test the connection to the projector before the session begins.

\section{Speaker information}

The location of your session is shown in the Abstracts section of the Conference Programme book and in the Pocket Programme. Please be on time for your session, check in with the session chair, and test the A/V equipment.

Time your presentation to fit the allotted time ( 22 minutes for each speaker) including time for questions and audience participation. Presentations should be limited to key issues with a brief summary. Feel free to bring along copies of your paper to distribute or to provide a handout with related information.

No proceedings with complete papers are produced for this meeting. To obtain complete copies of any papers abstracted in the program, please contact the authors directly at the address supplied with each abstract.

\section{For assistance during your session}

One session assistant (student volunteer) will be available at each room. If you have problems in your session room related to $\mathrm{AV}$ needs, if you have any other requests, address them to a student volunteer in the area to ask for assistance. 


\section{GENERAL INFORMATION}

\section{Basic Information}

- Vilnius Time Zone: GMT + 2 hours

\section{Usefull Telephone Numbers}

- Emergency Phone Number: 112

- Vilnius Airport: +37052306666

- Vilnius Bus Station: +37090001661

- Vilnius Rail Station: +370 52330088 ; +370 52330087

- Tourism Information Center: +37052629660

\section{Working Hours}

- Banks: approximately 9 am $-6 \mathrm{pm}$

- Pharmacies: approximately 9 am -6 pm

- Shops: approximately $10 \mathrm{am}-6 \mathrm{pm}$

- Shopping malls: approximately $10 \mathrm{am}-10 \mathrm{pm}$

- Embassies: approximately 9 am -5 pm

\section{Banks and Money}

Lithuania's currency: Litas $(\mathrm{Lt}) .1 € \approx 3,45 \mathrm{Lt}$. Euro $(€)$ is not accepted.

Major credit cards are accepted in most hotels, shops and restaurants. Traveller cheques or personal cheques are rarely used. Cash withdrawal machines linked to international networks are widely available.

\section{Electricity Network}

Lithuania has a voltage of $220 \mathrm{~V}$, an electrical frequency of $50 \mathrm{~Hz}$ and accepts two of the european standard plug (socket) type C or F.

\section{Public Transportation and Fares:}

- Taxis

Numerous taxis are operating in Vilnius. Taxis hired in the street can be more expensive. It is recommended to call Martono Standart Taxi 1422 (short local number) or +37052400004 . This is the only taxi company in Vilnius that you can pay for services by credit card. The price for a taxi from Vilnius airport to the centre of Vilnius is around $€ 15$.

Other taxi numbers: $+37052444999 ;+37052611111 ;+37052444777 ;+37052755555$.

\section{- Buses and trolleybuses}

Participants of EURO XXV can use public Vilnius City Transport for free. Please wear your badge at all times while using the transport.

Most routes run from 05:00 until around 23:00 or a little later. Single tickets for regular city buses and trolleybuses can be purchased from any "Lietuvos Spauda" kiosk or directly from the driver.

Price of single ticket: $2 \mathrm{Lt}$ if purchased at kiosk/2,5 Lt if purchased on bus. 
$25^{\text {th }}$ European Conference on Operational Research

\section{STATISTICS}

Number of Presentations: 1918

Number of Sessions: 524

Number of Participants: 2119

Conference participants by country:

\begin{tabular}{|c|c|}
\hline ALGERIA & 15 \\
\hline ARGENTINA & 2 \\
\hline AUSTRALIA & 22 \\
\hline AUSTRIA & 31 \\
\hline AZERBAIJAN & 1 \\
\hline BELARUS & 14 \\
\hline BELGIUM & 57 \\
\hline BOSNIA HERZEGOVINA & 1 \\
\hline BRAZIL & 69 \\
\hline BULGARIA & 1 \\
\hline CANADA & 38 \\
\hline CHILE & 23 \\
\hline COLOMBIA & 7 \\
\hline CROATIA & 17 \\
\hline CZECH REPUBLIC & 29 \\
\hline DENMARK & 19 \\
\hline EGYPT & 3 \\
\hline ESTONIA & 3 \\
\hline FINLAND & 33 \\
\hline FRANCE & 118 \\
\hline GERMANY & 245 \\
\hline GREECE & 29 \\
\hline HONG KONG & 6 \\
\hline HUNGARY & 6 \\
\hline INDIA & 19 \\
\hline INDONESIA & 14 \\
\hline IRAN & 32 \\
\hline IRELAND & 6 \\
\hline ISRAEL & 21 \\
\hline ITALY & 86 \\
\hline JAPAN & 58 \\
\hline LATVIA & 23 \\
\hline LITHUANIA & 25 \\
\hline LUXEMBOURG & 5 \\
\hline
\end{tabular}

\begin{tabular}{|c|c|}
\hline MALAYSIA & 2 \\
\hline MEXICO & 8 \\
\hline MOLDOVA & 2 \\
\hline NEW CALEDONIA & 1 \\
\hline NEW ZEALAND & 4 \\
\hline NIGER & 2 \\
\hline NORWAY & 34 \\
\hline PHILIPPINES & 1 \\
\hline POLAND & 54 \\
\hline PORTUGAL & 82 \\
\hline REUNION ISLAND & 1 \\
\hline ROMANIA & 13 \\
\hline RUSSIA & 36 \\
\hline SAUDI ARABIA & 6 \\
\hline SERBIA & 13 \\
\hline SINGAPORE & 3 \\
\hline SLOVAK REPUBLIC & 10 \\
\hline SLOVENIA & 10 \\
\hline SOUTH AFRICA & 16 \\
\hline SPAIN & 157 \\
\hline SWEDEN & 13 \\
\hline SWITZERLAND & 35 \\
\hline TAIWAN & 53 \\
\hline TANZANIA & 1 \\
\hline THE NETHERLANDS & 51 \\
\hline TUNISIA & 3 \\
\hline TURKEY & 177 \\
\hline UKRAINE & 26 \\
\hline UNITED ARAB EMIRATES & 2 \\
\hline UNITED KINGDOM & 151 \\
\hline URUGUAY & 1 \\
\hline USA & 70 \\
\hline VENEZUELA & 1 \\
\hline ZIMBABWE & 2 \\
\hline
\end{tabular}




\section{N $/ N$ U N

\section{EURO AWARDS AND PRIZES}

\section{EURO Gold Medal (EGM 2012)}

The EURO Gold Medal is the highest distinction within OR in Europe. It is conferred on a prominent person for an outstanding contribution to Operational Research. The prize recipient has a recognized stature in the European OR community and the award will be officially bestowed at the opening session of EURO XXV.

Members of the 2012 Jury:

- Aharon Ben-Tal (Israel) - Chair

- Rüdiger Schultz (Germany)

- Ger Koole (The Netherlands)

- Catherine Roucairol (France)

- Jeff Griffiths (UK)

\section{EURO Distinguished Service Medal (EDSM 2012)}

The EURO Distinguished Service Medal is awarded for recognition of distinguished service to the Association of European OR Societies (EURO) and to the profession of OR. The 2012 laureate has an extraordinary profile of long-standing involvement and influence on the discipline. The award will be officially presented at the opening session of EURO XXV.

Members of the 2012 Jury:

- Alexis Tsoukiás (France) - Chair

- Zilla Sinuany-Stern (Israel)

- Jan Węglarz (Poland)

- Maurice Shutler (UK)

- Laureano Escudero (Spain)

\section{EURO Doctoral Dissertation Award (EDDA 2012)}

The purpose of the EURO Doctoral Dissertation Award is to distinguish an outstanding PhD thesis in Operational Research, defended in a country which has an OR society that is member of EURO. Finalists will present their work at a special session on Monday morning. The award will be presented to the winner at the closing session of EURO XXV.

Members of the 2012 Jury:

- Jacques Teghem (Belgium) - Chair

- Silvano Martello (Italy)

- Hartmut Stadtler (Germany)

- Stéphane Dauzère-Pérès (France)

- Ahti Salo (Finland) 


\section{EURO Excellence in Practice Award (EEPA 2012)}

The EURO Excellence in Practice Award is for the best submission and presentation describing an application of Operational Research in practice. This year there are six finalists who will present their work over two special sessions on Monday. The award will be presented to the winner at the closing session of EURO XXV.

Members of the 2012 Jury:

- Michel Bierlaire (Switzerland) - Chair

- Luca Maria Gambardella (Switzerland)

- Gautier Stauffer (France)

- Richard Hartl (Austria)

- Ana Viana (Portugal)

\section{EURO/ROADEF Challenge 2012}

The EURO/ROADEF Challenge is an international Operational Research competition where teams have to solve an industrial optimization problem. Thanks to the success of the previous seven challenges the French Operational Research and Decision Support Society (ROADEF) organised, jointly with the Association of European OR Societies (EURO), the ROADEF/EURO Challenge 2012 dedicated to machine reassignment problem in collaboration with Google. The aim of this challenge is to improve the usage of a set of machines. A solution to this problem is a new process-machine assignment which satisfies all hard constraints and minimizes a given objective cost. Google proposed three prizes: 5000 Euros for the "senior category", 5000 Euros for the "junior category" and 10000 Euros for the Open Source category. Finalists will present their work in a dedicated stream during the conference and prizes will be awarded to the winners at the closing session of EURO XXV.

Members of the 2012 Jury:

- Christian Artigues (France) - Chair

- Eric Bourreau (France)

- Murat Afsar (France)

- Safia Kedad-Sidhoum (France)

- Ender Ozcan (UK)

- Emmanuel Gueré (France)

\section{EURO Award for the Best EJOR Paper (EABEP 2012)}

EURO has 3 new annual awards available for papers published by EJOR: best survey paper; best application paper; and best theory/methodology paper. Winners for each category have been selected by a jury and the first of these new awards will be presented at the closing session of EURO XXV.

Members of the 2012 Jury:

- David Pisinger (Denmark) - Chair

- José Fernando Oliveira (Portugal)

- Gerhard Woeginger (The Netherlands)

- Roman Slowinski (Poland)

- Horst Hamacher (Germany) 


\section{INVITED SPEAKERS}

\section{PLENARY SESSIONS}

Monday, 16:30 - 17:30, Opera

Chair: Marielle Christiansen, Norwegian University of Science and Technology, Trondheim, Norway

Finn Kydland

University of California, Santa Barbara, USA

Finn Kydland is the Jeffrey Henley Professor of Economics at the University of California, Santa Barbara, and 2004 Nobel Laureate in Economic Sciences. Professor Kydland received his B.A. from the Norwegian School of Economics (abbreviated NHH in Norwegian), and his Ph.D. from Carnegie Mellon University (CMU). After previous appointments at

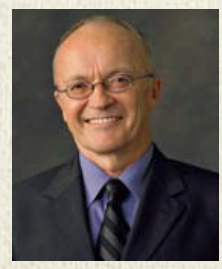

$\mathrm{NHH}, \mathrm{CMU}$, and the University of Texas at Austin, he joined the UCSB faculty in 2004, where he is also the director of the Laboratory for Aggregate Economics and Finance. He is an Adjunct Professor at CMU, $\mathrm{NHH}$, and University of Stavanger, and a Research Associate for the Federal Reserve Banks of Dallas and St. Louis. He was elected a Fellow of the Econometric Society in 1992.

Professor Kydland was awarded the Nobel Prize jointly with Professor Edward Prescott of Arizona State University. Professors Kydland and Prescott received the Nobel Prize for their research on business cycles and macroeconomic policy, specifically, the driving forces behind business cycles and the time inconsistency of economic policy. More recently, Professor Kydland has conducted research on the role of monetary policy in the aggregate economy, domestically as well as internationally. For example, why have nominal variables, such as the aggregate price level and nominal interest rates, been much more synchronized, cyclically, across major nations than real aggregates, such as real GDP? In the housing arena, empirically residential investment leads the cycle significantly in some nations, but not in others. How is this regularity related to the nature of mortgage contracts in the respective countries, in particular to the relative prevalence of fixed versus flexible nominal interest rates? What role does monetary policy play in this regard? Finally, Professor Kydland has studied Ireland and Argentina with the idea in mind that there is a lot for other nations' policymakers to learn from the respective successes and failures of these two nations.

\section{Dynamic Programming and Economics}

All interesting phenomena in macroeconomics are dynamic in nature. An overstatement, perhaps, but only a slight one. As a consequence, over the past three or four decades, dynamic programming has been an essential tool, including in my own research. In quantitative aggregate economics, dynamic programming plays a key role from model formulation to model calibration to computation of model outcomes. In the process, for example, of calibrating a model economy, its steady-state relations are an essential part of what it takes to work backwards from empirical relations among variables to what the model parameters must be in order to be consistent with them. With advances in the development of theory and computers becoming much more powerful, the set of interesting questions that can be addressed with such models has expanded dramatically in the past decade or two. This is true especially for questions that dictate the inclusion of important heterogeneity across current generations and/or across individuals more generally.

In models with a role for the government, anticipated future policy affects economic behavior in earlier periods. For example, future tax policy affects investment behavior today. If we imagine policy to be selected so as to optimize an objective (welfare) function, the resulting policy, in the absence of a commitment mechanism, is generally time inconsistent. Aside from questions about its implementation, then, a consequence is that the formulation of the optimal-policy problem is not recursive. But one can generally convert such a model into a recursive structure by introducing an additional pseudo-state variable a shadow price - which is subject to its own constraint implied by the model. Similar issues about recursivity, potentially resolved in an analogous manner, arise in many dynamic contracting environments. 
Tuesday, 16:30 - 17:30, Opera

Chairs: M. Grazia Speranza, President of EURO

Gerhard Wäscher, President-Elect of EURO

\section{Hans-Jürgen Zimmermann}

RWTH Aachen, Germany

Hans-Jürgen Zimmermann received his Bachelor in Engineering from Darmstadt Institute of Technology, his Masters in Engineering and his Ph.D. in Mathematical Economics and Business Administration from the Technical University of Berlin. After postgraduate studies at the University of Oxford he held various positions in industry, he was Professor

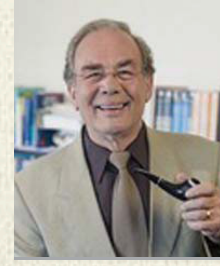
at the University of Illinois and has been teaching at various universities in India, Europe and the USA. He was Chairman of the Department for Operations Research at the Aachen Institute of Technology until July 31,1999 . He was then emerited but is still active at the university. He is also Scientific Director of ELITE (European Laboratory for Intelligent Techniques Engineering) and INFORM GmbH in Aachen.

He has published more than 250 papers in the areas of Operations Research, Decision Theory, Fuzzy Set Theory, and Computational Intelligence and 40 books in English and German in similar areas. He was Editor-in-Chief of the International Journal for Fuzzy Sets and Systems from 1978 till 1999, Editor of the European Journal for Operational Research from 1976 till 1999 and is still editor of the book series International Series in Intelligent Technologies, and Editor or Co-Editor of another 12 International Journals.

He received his first Honorary Doctorate from the Free University of Brussels and his second Honorary Doctorate from the Abo Akademi University, Finland. In 1985 he received the first EURO Gold Medal, and the S. Fu Certificate of Appreciation, the highest distinction of the "North American Fuzzy Information Processing Society" and in 1993 the Moisil Prize and Gold Medal. In 1997 he received the Kaufmann Prize:Gold Medal for Excellence in Uncertainty Research in Management, and in 1998 the EURO Pass in Gold. In 1999 he became the first Honorary Member of GOR, the German Operations Research Society, the first Fellow of IFSA(International Fuzzy Systems Association) and he received the European Pioneers Award by EUSFLAT (the European Fuzzy Systems Society). In 2011 he received the Fuzzy Pioneers Award by IEEE.

He has been founder and President of the German Operations Research Society (DGOR), the European Associations of Operational Research Societies (EURO), IFSA (International Fuzzy Systems Association), President of the German Industrial Engineering Society (VWI), and EEMA (European Engineering and Management Associations). He has also been Vice President of IFORS (International Federation of Operational Research Societies) and some other professional associations. Dr. Zimmermann has been organizer or chairman of numerous national and international conferences, amongst others of EURO XI in Aachen.

\section{Years of EURO: History, Applications, Future Potentials}

40 years ago, i.e. in 1972, the world looked quite different from to-day: Logistics were slower and more complicated: The best way to travel from Europe to the USA was by ship,which took between 5 and 13 days. Alternatively one could take a "Super Constellation" and go via Island in 24 hours. There were no electronic booking systems, customs-and passport control at each European Border, but no security systems at airports, no terrorism and no hijacking of planes. Communication was as clumsy: No fax, no email, no courier services, a letter between Europe and oversees took two to three weeks, each single letter had to be typed, and there were neither social nets nor a www. Professionally there existed three large OR - journals (and a number of small national ones), East and West was separated by the Iron Curtain. "Large" OR - Societies existed in the USA, Japan and Great Britain and in Europe there were a dozen of smaller national OR Societies. There was hardly any communication between these European societies and if one wanted to know what was going on in OR in another European country, the best way was, to ask a colleague in the USA. In the USA Ackoff had stated ( in 1979) "American Operations Research is dead though not yet buried". 
Under these circumstances the presidents of the European OR societies met at the IFORS conference 1972 in Dublin and came to the conclusion, that this situation of OR in Europe was sub-optimal and should be improved. They met again in 1973 and 1974 and decided to organize the first European OR conference at the end of January 1975 in Brussels. There were 500 participants and the representatives of 10 European countries. In the framework of this conference EURO was founded, 7 European working groups were started, the EURO - bulletins was started and it was decided to prepare the publication of a European OR journal (EJOR).

In the meantime EURO has 30 member countries, several professional journals, about 30 working groups, several very successful types of events, several prizes and awards, a very impressive web-page, and has had 25 successful EURO conferences. Hence: EURO has turned out to be a very successful organization.

The success of OR can, however, not only be measured by the manifold growth of EURO! As an applied discipline the situation of OR in Europe should also be considered from the point of view of available OR - tools, from its public visibility, the areas of applications, the education in this area, and its relationship to other disciplines that have emerged in the meantime and are relevant for OR. In some of these dimensions OR can certainly also be considered to be very successful. In others there are still or again big challenges that have to be met, if OR is also to be successful in the future. In this presentation some of these challenges will be considered in more detail and some ways suggested, how they can possibly be met.

Wednesday, 16:30 - 17:30, RB-Alfa

Chair: Dominique de Werra, EPFL, Lausanne, Switzerland

\section{Ralph E. Gomory (IFORS Distinguished Lecturer)}

New York University, USA

Ralph Gomory was born in New York, USA. in 1929. He graduated from Williams College in 1950, studied at Cambridge University, and received his Ph.D. in mathematics from Princeton University in 1954. Gomory then served in the U.S.Navy (1954-57) and then was a Higgins Lecturer and Assistant Professor of Mathematics at Princeton before joining IBM's newly formed Research Division in 1959 as a research mathematician.

In his student and graduate student years (Williams, Cambridge, Princeton), Gomory published papers on nonlinear differential equations, but his years in the Navy turned his attention to the applied mathematics of operations research. Back at Princeton he obtained the first general cutting-plane algorithms, which established the field of integer programming.

At IBM Research in the early 1960's, Gomory published papers with Paul Gilmore on the knapsack, traveling salesman and cutting-stock problems, and with T. C. Hu on flows in multi-terminal networks and continua. In the late 1960's, he developed the asymptotic theory of integer programming and introduced the concept of corner polyhedra. In the early 1970's, he collaborated with Ellis Johnson in investigating subadditive functions related to corner polyhedra that could also play a role in producing cutting-planes.

Gomory became Director of Research for IBM in 1970, with line responsibility for IBM's Research Division. During his 18 years as Director of Research the Research Division made a wide range of contributions to IBM's products, to the computer industry, and to science. The Zurich Research Laboratory did the work that resulted in two successive Nobel Prizes in physics, Yorktown Heights Research was the birthplace of what is now known as RISC architecture, and San Jose was the birthplace of the concept, theory and first prototype of relational databases.

Gomory, who had become the IBM Senior Vice President for Science and Technology retired from IBM in 1989 and became President of the Alfred P. Sloan Foundation. During his tenure as President he led the foundation into a long list of fields relevant to major national and scientific problems. The foundation pioneered in on-line learning and organized the worldwide Census of Marine Life. In 2007, after 18 years as President, Gomory became President Emeritus and joined New York University as a Research Professor. 
Gomory is a member of the U.S. National Academy of Sciences, the U.S. National Academy of Engineering, and the American Philosophical Society. He has been awarded eight honorary degrees and many prizes including the Lanchester Prize in 1963, the Harry Goode Memorial Award of the American Federation of Information Processing Societies in 1984, the John von Neumann Theory Prize in 1984, the Medal of the Industrial Research Society in 1985, the IEEE Engineering Leadership Recognition Award in 1988, the National Medal of Science awarded by the President of the United States in 1988, the Arthur M. Bueche Award of the National Academy of Engineering in 1993, the Heinz Award for Technology, the Economy and Employment in 1998, the Madison Medal Award of Princeton University in 1999, the Sheffield Fellowship Award of the Yale University Faculty of Engineering in 2000, the International Federation of Operational Research Societies Hall of Fame in 2005, and the Harold Larnder Prize of the Canadian Operational Research Society in 2006.

In addition to his mathematical work Gomory has written on the nature of technology development, research in industry, and industrial competitiveness, and on models of international trade involving changing technologies and economies of scale. He is the author, with Professor William Baumol, of the book "Global Trade and Conflicting National Interests" MIT Press 2001.

\section{Forty Years of Corner Polyhedra}

This talk will discuss the evolution of corner polyhedra from their beginnings in the study of Stock Cutting problems. We will discuss both their practical and theoretical aspects. We will see that corner polyhedra are by themselves the simplest integer programs and therefore might be expected to be more amenable to analysis than the more complex I.P. $s$ of which they are always a part. This expectation is fulfilled by some theoretical insights gained from corner polyhedra. The practical linkage stems from the fact that cutting planes for corner polyhedra are cutting planes for the complex practical problems of which they are a part. No knowledge of corner polyhedra is assumed in this talk.

\section{KEYNOTE AND TUTORIAL SESSIONS}

Monday, 8:30 - 10:00, RB-Alfa

Chair: Vincent Mousseau, LGI, Ecole Centrale Paris, France

\section{Ignacio Grossmann (Keynote Speaker)}

Carnegie Mellon University, Pittsburgh, USA

Professor Ignacio E. Grossmann is the R. R. Dean University Professor of Chemical Engineering at Carnegie Mellon University. He obtained his B.S. degree at the Universidad Iberoamericana, Mexico City, in 1974, and his M.S. and Ph.D. at Imperial College in 1975 and 1977, respectively. He joined Carnegie Mellon in 1979, and was Department Head of Chemical Engineering from 1994 to 2002. He is currently director of the "Center for Advanced Process Decision-making," an industrial consortium that involves 20 petroleum, chemical, engineering and software companies. He is a member of the National Academy of Engineering and his major awards include the 1994 Computing in Chemical Engineering Award of AIChE, the 1997 William H. Walker Award of AIChE, 2009 Warren Lewis Award of AIChE, and 2011 Research Excellence in Sustainable Engineering Award. He was also named "One of the Hundred Chemical Engineers of the Modern Era" by AIChE in 2008.

The research interests of Ignacio Grossmann are in the areas of mixed-integer and logic-based optimization, stochastic programming, process synthesis, energy integration, process flexibility, planning and scheduling of batch and continuous processes, and supply chain optimization. He has authored more than 400 papers, several monographs on design cases studies, and the textbook "Systematic Methods of Chemical Process Design," which he co-authored with Larry Biegler and Art Westerberg. 


\section{Challenges in the Application of Mathematical Programming in the Enterprise- wide Optimization of Process Industries}

Enterprise-wide optimization (EWO) is a new emerging area that lies at the interface of chemical engineering and operations research, and has become a major goal in the process industries due to the increasing pressures for remaining competitive in the global marketplace. EWO involves optimizing the operations of supply, production and distribution activities of a company to reduce costs and inventories. A major focus in EWO is the optimization of manufacturing plants as part of the overall optimization of the supply chain. Major operational items include production planning, scheduling, and control. This talk provides an overview of major modeling and computational challenges in the development of deterministic and stochastic linear/ nonlinear mixed-integer optimization models for planning and scheduling for the optimization of plants and entire supply chains that are involved in EWO problems. We illustrate the application of these ideas in four major problems:

a) integration of planning and scheduling in batch processes that lead to large-scale mixed-integer linear programs,

b) optimization of responsive process supply chains that lead to large-scale bicriterion mixed-integer optimization problems,

c) optimization of distribution-inventory planning of industrial gases that lead to integration of planning and vehicle-routing models,

d) optimization of oilfield infrastructures under uncertainty that lead to multistage stochastic programming problems with endogenous uncertain parameters.

We outline the solution methods that have been developed. Also, these problems have been addressed in collaboration with industry, and have led to substantial economic savings.

Monday, 10:30 - 12:00, RB-Alfa

Chair: Elena Fernández, Technical University of Catalonia, Barcelona, Spain

\section{Erhan Erkut (IFORS Invited Tutorial Speaker) Ozyegin University, Istanbul, Turkey}

Prof. Erkut obtained an undergraduate degree from the Faculty of Engineering of Bogazici University in 1980 and a Ph.D from the University of Florida in 1986, both in Industrial Engineering. Between 1985 and 2005, he taught at the University of Alberta's School of Business, and was a visiting faculty member at the Univ. of Geneva, Ohio State Univ., NIDA (Bangkok), as well as Bogazici and Sabanci Universities. He received nine teaching awards, including the prestigious "INFORMS Teaching of Management Science Practice Award" and Canada's "3M Teaching Fellowship," as well as five awards of merit, and four practice awards from the Canadian Operational Research Society.

Prof. Erkut, served as project leader for a number of externally-funded projects, founded an applied research center (Center for Excellence in Operations) at the University of Alberta, was the Founding Editor of INFORMS Transactions on Education, and published over 50 refereed journal articles in journals such as Operations Research, Transportation Science, European Journal of Operational Research, Interfaces, Computers \& OR, Risk Analysis, and Geographical Analysis. He served as Dean of the Faculty of Business Administration of Bilkent University between 2005 and 2007, before starting to serve as the Founding Rector of Ozyegin University in 2008.

\section{How to Make OR the Most Liked Course in the Curriculum?}

As teachers of OR, many of us would like to think that OR is one of the most valuable topics in university education. However, past experience shows that some of the students in our classrooms may not agree with this. How do we close this perception gap, and attract the best students to OR? This is just another problem, and if we think we are the best-trained problem solvers in the world, we should be able to overcome it easily. XXVII 
Unfortunately, while we may have exceptional training in analytical thinking and quantitative analysis, many of us lack the tools necessary for strategic planning, brand creation, and reputation management. Furthermore, most of us lack formal training in teaching, which makes matters worse.

My colleagues at the University of Alberta and I have experimented with various methods and tools over two decades, and we established that an OR curriculum can be very successful even in a business school - a considerably more challenging environment than an engineering school. The winning recipe includes ingredients such as spreadsheets, real-time modeling ("slow learning"), course management system, web tools, on-line communication, large classes, labs, student assistants, videos, guest speakers, on-line exams, and group projects; all delivered with a heavy emphasis on applications, and with a student-centered pedagogical approach. The results have been very positive; the reputation of the introductory course became "most useful", many of the best students took our electives, all members of our team won teaching awards, and through our collaboration with the industry we established a know-how transfer unit called Centre for Excellence in Operations.

In this tutorial, I will describe the problem we faced, and our attempts to solve it with examples of what worked and what did not, with an emphasis on what audience members could transfer to their institutions. The focus is not only on making one course popular, but on managing the entire student supply chain, complete with a student club, competitions, conferences, internships, and graduate programs. If you are interested in improving the perception and image of OR in your institution through teaching (and strategic planning), you are welcome to attend this session.

Monday, 12:30 - 14:00, RB-Alfa

Chair: Gerhard-Wilhelm Weber, Middle East Technical University, Ankara, Turkey

\section{Ceyda Oguz (Keynote Speaker)}

Koc University, Istanbul, Turkey

Ceyda Oguz is Professor of Industrial Engineering in College of Engineering at Koc University, Istanbul, Turkey. Before joining Koc University, she was a faculty member in the School of Business at The Hong Kong Polytechnic University, Hong Kong, from 1993 to 2004. She received her Ph.D. degree in Industrial Engineering from Bilkent University,

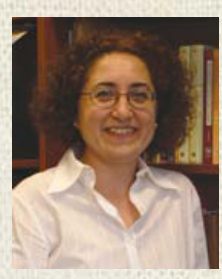
Turkey, in 1993 and holds an M.S. degree (Bilkent University) and a B.S. degree (Middle East Technical University) both in Industrial Engineering. Prof. Oguz conducts research in the areas of bioinformatics, logistics, and scheduling in manufacturing and computer systems. Her expertise includes algorithm design and system modeling as well as providing optimizing and/or approximate solutions to the complex systems by means of computational methods. Prof. Oguz has participated in several research projects, which were funded by TUBITAK and jointly by the Hong Kong and the European governments, related to above fields. She has published over 30 papers in refereed journals such as Operations Research, Computers and Operations Research and European Journal of Operational Research. Prof. Oguz took part in founding the "EURO Working Group on the Operational Research in Computational Biology, Bioinformatics and Medicine" (EURO-CBBM) and acts as the secretary and the treasurer of the group since 2006.

\section{Computational Biology and Operations Research}

Advancing the scientific understanding of organisms through computation has an ever-increasing importance that necessitates more research into fundamental problems of molecular biology. Research direction for these problems involves better analytical tools and more efficient algorithms due to massive volume of data. Hence computational biology can benefit from operations research area for developing mathematical models and devising efficient algorithms. In the literature, while integer programming and network models are usually employed at the modeling stage, dynamic programming, branch-and-bound algorithm, heuristics and metaheuristics are the prevalent computational methods employed for the problems. In this talk, I will give an overview of application of operations research methods to several computational problems that are XXVIII faced in molecular biology. 


\section{N N N
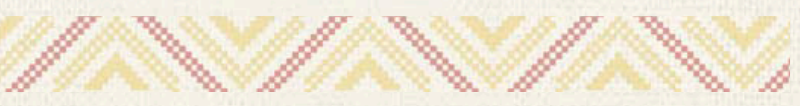 \\ $25^{\text {th }}$ European Conference on Operational Research \\ 8-11 July 2012. Vilnius, Lithuania}

Monday, 14:30 - 16:00, RB-Alfa

Chair: Marc Sevaux, Université De Bretagne-Sud, Lorient, France

\section{Kenneth Sörensen (Tutorial Speaker) \\ University of Antwerpen, Belgium}

Kenneth Sörensen is professor at the Faculty of Applied Economics of the University of Antwerp, where he also obtained his $\mathrm{PhD}$. Kenneth Sörensen chairs the research group ANT/OR (University of Antwerp Operations Research Group), a group that focuses on applications of Operations Research in diverse domains, and on the development of

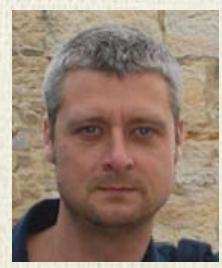
optimization algorithms, especially metaheuristics.

Kenneth Sörensen has published extensively on applied (heuristic) optimization and is a leading expert on the development of metaheuristics. He also founded the largest working group on metaheuristics: EU/ ME - the metaheuristics community.

\section{Metaheuristics - the Metaphor Exposed}

In recent years, the field of combinatorial optimization has witnessed a true tsunami of "new" metaheuristic methods, most of them based on a metaphor of some natural process. The behavior of virtually any species of insects, the flow of water, musicians playing together, it seems that no ideas are too far-fetched to serve as inspiration to launch yet another metaheuristic. In this tutorial, we will critically investigate whether the resulting methods are truly original, or just a repackaging of old ideas. In general, the usefulness of metaphorbased methods will be put to the test.

On the other side of the spectrum, researchers in metaheuristics are picking up ideas traditionally found in exact methods only, such as an intelligent decomposition of the problem and the use of exact methods to solve subproblems. In some problem domains such as vehicle routing or scheduling, a consensus is starting to condense on which ideas and which methods work and which do not. This is the result of many years of development of ever more powerful metaheuristics, combined with a careful study of the combinatorial properties of the problem. Additionally, deconstructing of a method, combined with statistical testing of the components and parameters of a metaheuristic can reveal those components and parameter settings that truly contribute to the performance.

The main aim of this talk is to provide some guidelines on how to develop an efficient and effective metaheuristic. We will show that the way forward is through the rigorous use of scientific methods, rather than through the indiscriminate introduction of yet another metaphor. 
Tuesday, 8:30 - 10:00, RB-Alfa

Chair: Gerhard Wäscher, Otto-von-Guericke University Magdeburg, Germany

\section{Anita Schöbel (Tutorial Speaker) \\ Georg-August University Göttingen, Germany}

Anita Schöbel is Full Professor at the Department of Mathematics and Computer Science at the University of Göttingen, Germany. After receiving her Doctor of Science degree in 1998 from the Technical University of Kaiserslautern she has been working at the Fraunhofer Institute for Industrial Mathematics (ITWM) growing a new group working in public transportation. In 2004 she changed to the university of Gottingen as an associate professor where she received a full professorship in 2007. Together with her family she spent a semester at the University of Auckland.

Her research interests are within the field of discrete optimization and include robust and multiobjective optimization. Her fields of applications are in location theory, in resource efficiency, and in public transportation planning where she works in research projects and in real-world applications. She is head of the EU project OptALI which supports an exchange between Europe and New Zealand, member of two DFG research training groups and conducting a project on robust optimization within the DFG priority programme "Algorithm Engineering".

Anita Schöbel is a member of the Editorial Board of the international journals "OR-Spectrum", "Journal of Optimization Theory and Applications (JOTA)", and "INFOR" and was in the Program Committee of several international meetings. She wrote two and edited six books, and she co-authored around 75 refereed papers most of them been published in international journals. Apart from her research in optimization, she is also interested in new and interdisciplinary teaching projects.

For further information about Anita Schöbel and her working group, see http://optimierung.math. uni-goettingen.de/.

\section{Lines, Timetables, Delays: Models and Trends in Optimization of Public Transport}

In the first part of the talk, an overview on line planning, timetabling, and delay management is provided. Given an existing public transportation network with its stops (or stations) and direct connections, the first step in the strategic planning of a transport system is to define lines and their frequencies. A line is a path in the public transportation network along which regular service is offered. We discuss various optimization models minimizing either the costs of the lines or maximizing the convenience of the passengers.

If the lines have been found, the next step is to design a timetable. There are two different models: Periodic timetables which are repeated on e.g. an hourly basis and aperiodic timetables. The usual aim is to minimize the traveling time for the passengers. Integer programming formulations will be provided for both problem types and algorithmic approaches for finding timetables will be reviewed.

Coming to the operational phase, we deal with the question of how to react in case of delays. This concerns the decision if a punctual bus or train should wait for a delayed feeder bus or train or if it should better depart on time. In railway traffic also the limited capacity of the tracks has to be taken into account, i.e. priority decisions have to be made. The state-of-the art of delay management will be presented.

In the second part we discuss recent research directions aiming at making the approaches work in practice. A challenging problem concerns the route choice of the passengers. In many papers it is assumed that it is already known how the passengers travel, i.e. a passenger's weight is assumed to be known for every edge or activity in the system. This is an unrealistic assumption since the route choice of the passengers depends on the lines, the timetable, and on the delay management strategy. We will discuss how the passengers decisions may be integrated into the optimization process.

Another issue is robustness. It is not helpful to have an exact optimal solution that might get meaningless if a small disturbance occurs. Hence, the aim should be to have a robust transportation system which performs well even if the scenario or the input data changes. We exemplary illustrate different concepts on how to develop robust timetables. The third research question concerns an integration of the subsequent planning steps, which is illustrated using our toolbox LinTim. 
Tuesday, 10:30 - 12:00, RB-Alfa

Chair: Marielle Christiansen, Norwegian University of Science and Technology, Trondheim, Norway

Guy Desaulniers (Tutorial Speaker)

Ecole Polytechnique de Montreal and GERAD, Montreal, Canada

Guy Desaulniers (www.gerad.ca/ guyd) received his BSc, MSc and PhD in mathematics from University of Montreal in 1987 and 1989, and from Ecole Polytechnique, Montreal, in 1993, respectively. Between 1993 and 2000, he worked as a professor or a researcher at College Militaire Royal de St-Jean, Ecole Polytechnique, and University Laval in Quebec

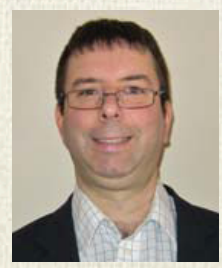

City. Since 2000, he is a professor in the department of applied mathematics and industrial engineering at Ecole Polytechnique. There, he was the head of the programs of graduate studies in mathematics from 2002 to 2010 and he is now the head of the undergraduate courses in mathematics. So far, he has supervised more than 50 graduate students and authored more than 60 papers, most of them published in renowned operations research journals. He also coedited a book on column generation and coorganized two summer schools and two international workshops on column generation. He has given talks in many international conferences and has been an invited speaker in five international events, including the German Operations Research conference in 2007. He has been involved in several industrial research projects.

The main research interests of Guy Desaulniers are in the areas of large-scale optimization (in particular, column generation), integer programming, combinatorial optimization, and constrained shortest path problems with applications to vehicle routing and crew scheduling in land, air, rail, and maritime transportation, and to personnel scheduling in any context.

\section{Years of Column Generation for the Vehicle Routing Problem with Time Windows}

Column generation is a well-known mathematical programming technique for solvinglarge-scale optimization linear problems. In the mid-1980s, it was shown that it can be successfully embedded in a branch-and-bound framework (yielding a branch - and - price method) for solving integer programs. Since then, it has become the most popular exact methododology for solving several classes of vehicle routing problems. As a fertile testbed, the vehicle routing problem with time windows (VRPTW) played an important role in this success. It consists of finding a set of least-cost vehicle routes to deliver goods to a set of customers. Each customer must be visited exactly once within a given time window and each route must respect vehicle capacity. In this talk, we survey the evolution of the column generation methods developed for the VRPTW, starting from the seminal work of Desrochers, Desrosiers, and Solomon (1992). In particular, we present various path relaxations proposed to avoid solving the NP - hard elementary shortest path subproblem, labeling algorithms used to generate their corresponding columns, and valid inequalities tightening the lower bounds, including those that are directly defined on the master problem variables. We discuss certain acceleration strategies, report computational results, and highlight current and future challenges. 
Tuesday, 12:30 - 14:00, RB-Alfa

Chair: Peter Letmathe, RWTH Aachen, Germany

\section{Bjorn Nybo Jorgensen (Keynote Speaker)}

Accounting and Business Law, University of Colorado at Boulder, USA

Bjorn Jorgensen holds a PhD in Accounting and Information Systems from Northwestern University and a MS in mathematical economics from University of Aarhus. He is the Tisone chair and currently serves as accounting division chair at the Leeds School of Business of the University of Colorado at Boulder. Prior to joining Colorado, he taught at

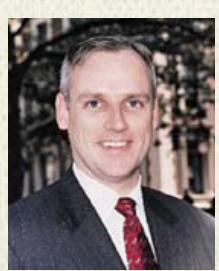
Columbia and Harvard and visited the U.S. Securities and Exchange Commission and the London School of Economics. His research interests focus on financial accounting and the disclosure and management of risk. His work is published in accounting, economics, and finance journals, including The Accounting Review, Annals of Finance, Annals of Journal of Econometrics, Applied Stochastic Models in Business and Industry, Contemporary Accounting Research, Journal of Accounting and Economics, and Journal of Business.

\section{Accounting}

This presentation uses optimization and stochastic processes to provide a formal introduction to disclosure, financial accounting, and valuation. Financial accounting produces balance sheets, income statements, and cash flow statements relying on two basic principles: Double entry bookkeeping and the accrual basis of accounting. Disclosure of financial accounting statements is today mandatory for publicly traded firms. A single-period benchmark setting is initially used to establish what disclosures would maximize firm value in the absence of mandatory disclosure.

Second, in a multi-period setting, the so-called clean surplus relation ties together consecutive balance sheets through comprehensive income from the income statement. Third, under the accrual basis of accounting, income decomposes into cash flows and accruals. Since accruals arise from the non-cash component of income such as depreciation, accruals must reverse over time in the sense that they add up to zero over the complete life cycle of the firm. I propose to model accruals as a moving average time-series process with a unit root. This modeling approach has implications for how market values relate to earnings, cash flows, and balance sheet book values.

Tuesday, 14:30 - 16:00, RB-Alfa

Chair: Stein W. Wallace, Lancaster University, UK

Jitka Dupacova (Tutorial Speaker)

Charles University, Prague, Czech Republic

Jitka Dupacova is Professor at the Department of Probability and Mathematical Statistics, Faculty of Mathematics and Physics, Charles University Prague. She received her PhD. degree in 1967 and the Doctor of Sciences degree in 1985 from the same faculty. Is scholar of the International Institute for Applied Systems Analysis, Laxenburg, Austria

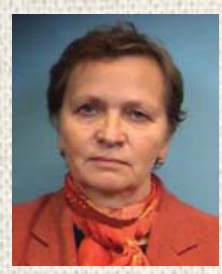

(1985-1986), member of various international and national scientific societies such as the Mathematical Optimization Society, the WG 7.7 of IFIP, EURO WG on Financial Modeling, the Czech Econometric Society and the Czech Operational Research Society.

She is known for her results in stochastic programming and related areas of statistics and optimization, which is also the subject of her dissertations, books and more than 150 published scientific papers with the $\mathrm{h}$-index 12. Is active in stochastic modeling in economics, finance, water resources management and planning, 
and other areas, took part in related projects of EC. She gave courses on stochastic programming, financial management and optimization in statistics at various Universities around the world and prepared special courses and lectures for Czech banks and for the Central Bank of Malta. In consideration of her merits in the development of stochastic programming she was awarded one of twelve memorial plaques during the $\mathrm{X}$. Symposium on Stochastic Programming (2004).

\section{Stochastic Programming - a Flexible Tool for Decision Making under Uncertainty}

To apply stochastic programming (SP) means primarily to be familiar with the real-life problem in question, its purpose, constraints, and with the available level of information concerning the driving random factors. Even when implementation of complex SP models does frequently require simplifications and/or approximations, their outcome may point at new decision strategies.

We shall focus on the modeling issues. The interplay between the problem setting and the SP model building will be illustrated on selected examples related mainly to water resources management and planning.

Wednesday, 8:30 - 10:00, RB-Alfa

Chair: Leonidas Sakalauskas, Vilnius University, Lithuania

Boris Polyak (Keynote Speaker)

Institute for Control Science, Moscow, United States of Russian Feredation

Boris T. Polyak received Ph.D. degree in mathematics from Moscow State University in 1963 and Doctor of Science degree in engineering from Institute for Control Science, Moscow, in 1977.

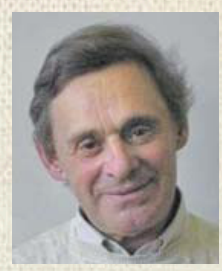

He is currently Head of Ya.Z.Tsypkin Laboratory, Institute for Control Science of Russian Academy of Sciences, Moscow, United States of Russian Feredation and Professor of Moscow Institute for Physics and Engineering. He is the author of more than 200 papers and 3 monographs, including Introduction to Optimization, Russian and English editions, and Robust Stability and Control, coauthored with P.S. Scherbakov. He is on the Editorial Boards of J. of Opt. Th. and Appl., Autom. and Remote Contr., Numer. Funct. Anal. and Opt., Comput. Opt. and Appl., and Appl., Contr. and Cybern. Head of Systems and Signals Group of Russian National Committee of IFAC. Recipient of Meyerhoff Fellowship (1991), Andronov's Award of Russian Academy of Sciences (1994), NATO Fellowship (1999), Award for the Best Paper published in Russian journals (2000, 2008). Visiting Professor at the Weizmann Institute of Science (1991), University of Madison-Wisconsin (1992, 1994), University of Paris-Sud (1995, 1997), Ecole Normal Superior-Cachan (1997, 2001, 2002), Politecnico di Torino (1999, 2000), CINVESTAV (2003). He is IFAC Fellow.

His research interests include mathematical programming, nonsmooth optimization, stochastic estimation and optimization, optimal control, robust stability analysis, robust design, chaos control, sparse filtering.

\section{Robust Eigenvector Problem and its Application to PageRank}

There are novel approaches to Robust Linear Programming and Robust Least Squares which convert them into nonsmooth convex optimization problems. We provide similar technique for robust eigenvector problem for stochastic matrices. Such robust formulations are natural for numerous ranking problems. The approach is compared with standard ones, such as PageRank. Numerical optimization algorithms for nonsmooth problems arising are addressed. 
Wednesday, 10:30 - 12:00, RB-Alfa

Chair: Silvano Martello, University of Bologna, Italy

\section{Matteo Fischetti (Keynote Speaker)}

University of Padua, Italy

Matteo Fischetti (http://www.dei.unipd.it/ fisch) was born in 1958. In 1982, he received his degree in Electrical Engineering (cum laude) at the University of Bologna. In 1987, he got his PhD degree in System Engineering at the University of Bologna. Since 1997, he is full professor of Operations Research at the Dipartimento di Ingegneria dell'Informazione of the University of Padova. His research interests include Integer Programming, Combinatorial Optimization, Graph Theory, Design and Analysis of Combinatorial Algorithms, Vehicle Routing and Crew Scheduling Problems, and Polyhedral Combinatorics.

$\mathrm{He}$ is member of the Editorial Board of the international journals "Mathematical Programming Computation", "Journal of Combinatorial Optimization", and "4OR".

He was the Program Committee chair of the international meetings "IPCO 2007" and "ATMOS 2008" and plenary speaker at the Mathematical Programming Symposium (Lausanne, 1997, and Chicago, 2009), at the EuroGP2005 \& EvoCOP2005 meeting (Lausanne, March 2005) and at the 1st Nordic Optimization Symposium (Copenhagen, April 2006).

Matteo Fischetti won the following scientific prizes:

$\square \quad$ First Prize "Best Young Researcher", awarded by A.I.R.O. (the Italian Operations Research Society), 1987;

- First International Prize "Best Ph.D. Dissertation on Transportation", awarded by the Operations Research Society of America (the first prize awarded by O.R.S.A. for a Ph.D. thesis developed outside USA), 1987;

口 First Prize "FASTER", awarded by FS-Ferrovie dello Stato for the best computer code for solving very large set-covering problems arising in railway scheduling (jointly with P. Toth and A. Caprara), 1994;

口 First Prize "FARO", awarded by FS-Ferrovie dello Stato for the best computer code for solving a crew scheduling problem arising in railway applications (jointly with P. Toth, D. Vigo and A. Caprara), 1995.

$\square$ Finalist of the INFORMS "Daniel H. Wagner Prize for Excellence in Operations Research Practice" with the paper "Reinventing Crew Scheduling at Netherlands Railways (jointly with Erwin Abbink, Leo Kroon, Gerrit Timmer, and Michiel Vromans), 2004.

- Winner of the INFORMS “Edelman award 2008" (the Oscar for OR practice) with the entry "Netherlands Railways - The New Dutch Timetable: The OR Revolution" (jointly with Leo Kroon, Dennis Huisman, Erwin Abbink, Pieter-Jan Fioole, Gabor Maroti, Lex Schrijver, Adri Steenbeek, Roelof Ybema), 2008.

He published more than 100 scientific papers on the top-level journals of the area, including Mathematics of Operations Research, Mathematical Programming, Operations Research, Management Science, European Journal of Operational Research, Networks, INFORMS Journal on Computing, Discrete Applied Mathematics, Journal of the American Statistical Association, IEEE Transactions on Knowledge and Data Engineering, etc.

\section{On the Role of Randomness in Exact Tree Search Methods}

High-sensitivity to initial conditions is generally viewed as a drawback of tree search methods, as it leads to an erratic behavior to be mitigated somehow. In this talk we address the opposite viewpoint. Our working hypothesis is that erraticism is just a consequence of the exponential nature of tree search, that acts as a chaotic amplifier, so it is largely unavoidable. We discuss possible ways to actually take advantage of randomness, and present computational experiments on a testbed of difficult MILP instances. 
Wednesday, 12:30 - 14:00, RB-Alfa

Chair: Richard Hartl, University of Vienna, Austria

\section{Jonathan Caulkins (Keynote Speaker)}

Carnegie Mellon University, Pittsburgh, USA

Jonathan P. Caulkins is H. Guyford Stever Professor of Operations Research and Public Policy at Carnegie Mellon University's Qatar Campus and Heinz College of Public Policy and Information Systems Management.

Dr. Caulkins specializes in systems analysis of problems pertaining to drugs, crime, terror, violence, and prevention - work that won the David Kershaw Award from the Association of Public Policy Analysis and Management, a Robert Wood Johnson Health Investigator Award, and the INFORMS President's Award. Other interests include reputation and brand management, software quality, optimal control, black markets, airline operations, and personnel performance evaluation. He has taught his quantitative decision making course on four continents to students from 50 countries at every level from undergraduate through Ph.D. and exec ed.

He has 100 refereed articles in journals includingEuropean Journal of Operational Research, Operations Research, Management Science, Lancet, Mathematical Biosciences, American Journal of Public Health, Addiction, Journal of Policy Analysis and Management, Healthcare Management Science, IEEE Security \& Privacy, SIAM Journal on Control and Optimization, Demographic Research, JOTA, JEBO, International Journal of Bifurcation and Chaos, Socio-Economic Planning Sciences, Journal of Environmental Economics and Management, and the Journal of the American Statistical Association.

Caulkins has authored or co-authored nine books including Drugs and Drug Policy: What Everyone Needs to Know (2011, OUP), Drug Policy and the Public Good. (2010, Oxford) and Optimal Control of Nonlinear Processes: With Applications in Drugs, Corruption, and Terror (2008, Springer). His latest book (June, 2012, OUP) is on marijuana legalization.

He is a past co-director of RAND's Drug Policy Research Center (1994 - 1996), founding Director of RAND's Pittsburgh office (1999-2001), and continues to work through RAND on a variety of government projects.

Dr. Caulkins received a B.S., and M.S. in Systems Science from Washington University, an S.M. in Electrical Engineering and Computer Science and Ph.D., in Operations Research both from M.I.T.

\section{Providing a Scientific Basis for Managing Illegal Drugs \& Markets}

What happens when formal training in operational analysis meets a classic "wicked problem" with multiple conflicting objectives, competing agency priorities, and abundant data that nevertheless do not answer the questions that really matter? This talk gives one answer, drawing on $20+$ years experience working on a particularly fascinating problem - policy regarding control of illegal markets, notably those for illegal drugs. The tools of operations research, industrial organizations, and economics can be harnessed to provide an empirical, scientific basis for drug policy making. The models discussed in this talk focus on drug initiation (product diffusion), price responsiveness (elasticity of demand), and operation of the illegal supply chain, both during normal times and when the distribution network is disrupted. Corresponding data are drawn from epidemiological studies, forensic laboratory analysis, undercover buys, and extensive interviews with incarcerated drug smugglers and dealers in Australia, France, the UK, and the US. These models provide the foundation for estimating the cost-effectiveness of different strategies for controlling drug use and associated social harms.

However, I will not tell an entirely happy tale of Operations Research (OR) as panacea, limited only by the outside world's ignorance of its power. Rather, I will tell a story of a glass that is half full and yet also half empty.

For example, these issues are truly "OR problems" in the sense that OR ideas and insights underpin key dynamics and in the sense that knowledge of OR empowers better understanding and solutions. However, 
they are also problems of and for economics, sociology, political science, demography, psychology, medicine, and other disciplines. OR can and should partner with other disciplines and perspectives when grappling with fundamental strategy choices related to drug policy.

Likewise, the adversarial nature of the policy making process challenges an optimization-based way of looking at the world.

The objective of this talk is to reflect on OR's success and limitations in this and some allied domains to draw meta lessons for how experts can effectively use mathematical models and operational analysis to produce insights that inform decision makers in comparably messy domains.

Wednesday, 14:30 - 16:00, RB-Alfa

Chair: Mikael Rönnqvist, Université Laval, Québec, Canada

\section{Karla Hoffman (Tutorial Speaker)}

George Mason University, Fairfax, USA

Karla Hoffman is a Professor in the Systems Engineering and Operations Research Department at George Mason University where she had been Chair for five years ending in 2001. She received her BS in mathematics from Rutgers University, and her MBA and D.Sc. from George Washington University. She worked as a mathematician in the Operations Research Department of the Center for Applied Mathematics of the National Institute of Standards and Technology where, in 1984, she was awarded the Applied Research Award for her research in solving large combinatorial optimization problems. Her other awards include George Mason University's Distinguished Faculty Award as well as the Volgenau School of Engineering Distinguished Research Award, The Harvey Greenberg Service Award, the INFORMS Fellows Award, the George E. Kimball Medal, the Omega Rho Lectureship. She was President of INFORMS in 1999 and has also served on the Executive Committees of ORSA and the Mathematical Programming Society. She currently serves as the North American Vice President to the International Federation of OR Societies (IFORS). Dr. Hoffman's primary area of research is auction design and testing, and combinatorial optimization. Her research focuses on the development of new algorithms for solving complex problems arising in industry and government. She is currently serves as a consultant to the U.S. Federal Communications Commission on spectrum auction design and testing and has served as a consultant to a variety of other US government agencies. the FAA on auction design for arrival and takeoff slots and had previously consulted to the FCC on spectrum auctions. She has developed crew and fleet scheduling algorithms for the airline industry, real-time scheduling algorithms for truck and bus transportation, consults to the military on a variety of routing and scheduling problems and has advised the telecommunications industry on capital budgeting.

\section{Auctions: Why they Proliferating and What You Need to Know to Participate}

The advent of the Internet has led to the creation of global marketplaces in which sales of everything from low-cost used merchandise to billion dollar government procurements are conducted by auction. While some auction designs have been extremely successful, others have failed disastrously. This talk will describe a variety of alternative auction designs, and will explore why one design is likely to be more appropriate than another for a given application. We will begin with a brief history of auctions, provide reasons for eBay's spectacular success, and highlight the Internet's impact on auction theory and practice. We will then move on to a discussion of the strategies that are available to bidders in the most-utilized auction formats, thereby providing each of you with hints on how to be more successful when participating in auctions. Throughout the talk, we will highlight the role that operations research analysts can play in designing, running, and assisting participants in business-to-business and high-stakes government auctions. 


\section{SPONSORS / EXHIBITORS}

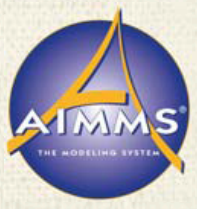

\section{AIMMS www.aimms.com}

AIMMS is the Advanced Integrated Mathematical Modeling System for developing and deploying optimization-based models and applications. With AIMMS you can enjoy a unique experience of interactive modeling as the tool supports every single step you undertake at the various stages of building an effective solution to your problem. From simple models to complex algorithms and real-life applications, AIMMS enables fast and flexible model formulation, data exchange, solver linkage, visualization, and deployment.

The AIMMS language offers tailored modeling concepts, automatically updated definitions and procedural execution around your model. While AIMMS links seamlessly to a wide range of powerful solvers, the model definition in AIMMS is solver-independent, allowing for easy switch and comparison between the various solvers. AIMMS has the integrated capability to build a Graphical User Interface based on a rich collection of graphical objects, allowing for an insightful visualization of the model data. AIMMS productivity and diagnostic tools further facilitate an efficient model development. Moreover, AIMMS provides extensive support for optimization under uncertainty, including specialized modules for Stochastic Programming as well as a dedicated Robust Optimization add-on.

A Free Academic License allowing for all features of AIMMS is available for students, professors, and researchers at universities. Moreover, this free license includes unrestricted word-class solvers such as CPLEX, GUROBI, MOSEK, CONOPT, MINOS, SNOPT, PATH, AOA, LGO, XA, IPOPT, or $\mathrm{CBC}$. Additionally, the Free Academic License allows the usage of the AIMMS Robust Optimization add-on for decision making problems under uncertainty.

\section{4 anpr}

\section{AMPL Optimization www.ampl.com}

AMPL is a comprehensive and powerful algebraic modeling language for linear and nonlinear optimization problems, in discrete or continuous variables.

Developed at Bell Laboratories, AMPL lets you use common notation and familiar concepts to formulate optimization models and examine solutions, while the computer manages communication with an appropriate solver.

AMPL's flexibility and convenience render it ideal for rapid prototyping and model development, while its speed and control options make it an especially efficient choice for repeated production runs. 


\section{Ba ADRDA $^{\circ}$}

AORDA www.aorda.com

American Optimal Decisions company consults on risk management, optimization, statistics and develops advanced optimization software. The primary software product is Portfolio Safeguard (PSG): http://www.aorda. com/aod/psg.action.

Portfolio Safeguard (PSG): Windows based optimization package for nonlinear and mixed-integer problems. PSG handles especially well optimization in uncertain environment (e.g., code for two-stage stochastic optimization problem includes only one line: $\min$ avg(recouse(data_set_with_matrices)).

The focus application areas of PSG:

- Financial Engineering

- Logistics

- Advanced Statistics

- Medical Applications

- Stochastic Programming

List of case studies with data and solutions are at these links:

http://www.aorda.com/aod/psg.action\#casestudies

http://www.ise.ufl.edu/uryasev/research/testproblems/

Main featurs of PSG:

- efficient numerical algorithms making fast and robust decisions: four solvers based on different principles;

- four environments: Windows Shell, MATLAB, C++, and Run-File Text

- advanced statistics: calibrating probability distribution with entropy, robust regression minimizing difference of percentiles, support vector machines with $\mathrm{CVaR}$ functions, etc.

- optimizes Probability, Value-at-Risk (VaR) and other tail risk measures such as CVaR, Drawdown, Low Partial Moment, Omega, and Maximum Loss with cardinality and buy-in constraints, fixed-charge functions, etc. PSG addresses a wide range of quantitative finance problems, such as portfolio optimization, asset allocation, selection of insurance, hedging derivative contracts, bond matching, credit risk minimization, and structuring of Collateralized Debt Obligation (CDO).

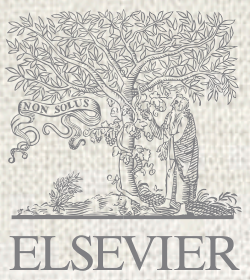

\section{ELSEVIER B.V. www.elsevier.com/mathematics}

Elsevier is the leading journals publisher in the field, working in partnership with the global academic community to publish 12 of 20 top ranked journals in the "Operational Research and Management Science category in the Social Citation Index, including the European Journal of Operational Research. Within the "Discrete Mathematics" category Elsevier provides a forum for mathematical, computational and applied aspects of research in areas of combinatorial. Algorithmic and applicable discrete mathematics. 


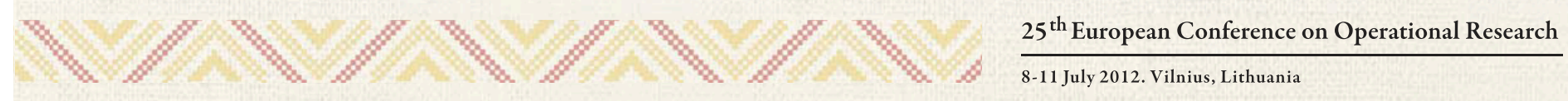

FICO (NYSE:FICO) is a leader in Decision Management, transforming business by making every decision count. FICO uses predictive analytics and optimization to help businesses automate, improve and connect decisions across organizational silos and customer lifecycles. FICO develops and markets the FICO Xpress Optimization Suite - with its unique Mosel modeling language (www.fico.com/xpress). Clients in 80 countries work with FICO to increase customer loyalty and profitability, cut fraud losses, manage credit risk, meet regulatory and competitive demands, and rapidly build market share. Most leading banks and credit card issuers rely on FICO solutions, as do insurers, retailers, health care organizations and other companies. FICO works with more than 5,000 businesses worldwide, and its technology serves thousands more through FICO partnerships.

\section{GUROBI} OPTIMIZATION

\section{Gurobi Optimization www.gurobi.com.}

Gurobi Optimization provides high performance LP, QP, QCP, and MIP solvers using the most advanced implementations of the latest algorithms. We offer best-in-class performance, support a broad range of interfaces and modeling languages, and offer flexible licensing together with transparent, no surprises, pricing. Plus we back all this with outstanding, easy to reach support. Founded by arguably the most experienced and respected team in optimization today, Gurobi is rapidly growing as more and more companies see the benefits of working with a partner so focused on providing the best solver and the best support possible. More information, including pricing, benchmark data, and free trial downloads, are available on our website at www.gurobi.com.

\section{LocalSolver LOCALSOLVER wwwlocalsolver.com}

Resulting from a 5-year R\&D project involving distinguished experts in computational optimization, LocalSolver is the first math programming software combining the simplicity of use of a model-and-run solver and the power of local-search techniques for combinatorial optimization. Having declared your optimization model using mathematical operators, LocalSolver will provide you with high-quality solutions in very short running times without any tuning. Relying on local search, LocalSolver is able to scale up to 10 million binary decision variables, running on standard computers.

- Solve highly nonlinear models

- Goal programming made easy

- Scale up to 10 million variables

- Pure model-and-run solver

LocalSolver is particularly suited for solving large-scale real-life combinatorial problems arising in business and industry. Such problems, with millions of variables, are totally out of scope of current state-of-the-art solvers which all based on classical tree-search techniques (integer or constraint programming). 
- Nonlinear assignment: car sequencing, frequency assignment

- Packing \& Covering: media planning, machine scheduling

- Facility location, logistic clustering, network optimization

- Workforce scheduling, group planning, nurse rostering

Palgrave Macmillan+ logo www.palgrave-journals.com

\section{palgrave macmillan}

\section{黛 Springer}

\section{Palgrave Macmillan}

Palgrave Macmillan is proud to be the publisher of The OR Society. Founded over 50 years ago, it is the world's oldest Operational Research society, and one of the largest in the world. The six journals of the OR Society will bring your institution the perfect combination of pedigree, longevity and cuttingedge research and practice.

This year we are delighted to launch the latest addition to that portfolio - Health Systems. (www.palgrave-journals.com/hs/ <http://www. palgrave-journals.com/hs/ >) It is a new interdisciplinary journal promoting the idea that all aspects of health and healthcare delivery can be viewed from a systems perspective. Come to our stand to pick up a sample copy!

Also available will be information on IAOR Online and the Journal of Revenue and Pricing Management. We look forward to meeting you.

\section{Springer}

Springer is the proud publisher of the EURO Journal on Transportation and Logistics and the forthcoming EURO Journal on Computational Optimization and EURO Journal on Decision Processes. Please stop by our exhibit where staff will be on hand to answer any questions about publishing in the EURO Journals as well as to discuss any ideas you may have about publishing a book with Springer. We will be showcasing some of our newest books in Operations Research, which will be available for purchase at a special $20 \%$ discount.

\section{TAYLOR \& FRANCIS www.tandf.co.uk/journals}

Building on two centuries' experience, Taylor \& Francis has grown rapidly over the last two decades to become a leading international academic publisher. Operating from a network of 20 global offices, including New York, Philadelphia, Oxford, Melbourne, Stockholm, Beijing, New Delhi, Johannesburg, Singapore and Tokyo, the Taylor \& Francis Group publishes more than 1,500 journals and around 1,800 new books each year, with a books backlist in excess of 20,000 specialist titles. 
OVERVIEW OF THE PROGRAMME

\begin{tabular}{|c|c|c|c|c|c|c|c|c|c|c|c|c|c|c|c|c|c|}
\hline & \begin{tabular}{l}
8 \\
$\ddot{0}$ \\
0 \\
\hdashline \\
$\delta$ \\
$\ddot{0}$ \\
$\ddot{0}$
\end{tabular} & $\begin{array}{c}0 \\
\stackrel{0}{0} \\
\ddot{0} \\
1 \\
\dot{0} \\
\dddot{\infty} \\
\ddot{\infty}\end{array}$ & 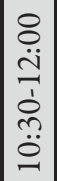 & 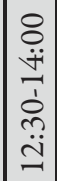 & 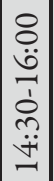 & 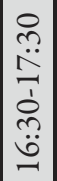 & $\begin{array}{c}0 \\
0 \\
0 \\
1 \\
1 \\
0 \\
\ddot{\infty}\end{array}$ & $\begin{array}{l}8 \\
\ddot{U} \\
\ddot{1} \\
\dot{0} \\
\ddot{n} \\
\ddot{\theta}\end{array}$ & 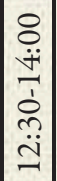 & 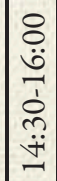 & 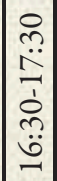 & $\begin{array}{c}0 \\
0 \\
\ddot{0} \\
1 \\
0 \\
\\
\ddot{\infty}\end{array}$ & 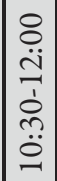 & 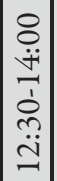 & 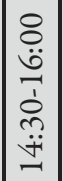 & 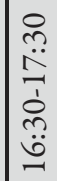 & 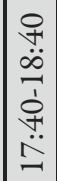 \\
\hline Stream & SA & MA & $\mathrm{MB}$ & $\mathrm{MC}$ & $\mathrm{MD}$ & ME & $\mathrm{TA}$ & $\mathrm{TB}$ & $\mathrm{TC}$ & $\mathrm{TD}$ & $\mathrm{TE}$ & WA & WB & WC & WD & WE & WF \\
\hline \multicolumn{18}{|l|}{ Opening session } \\
\hline \multicolumn{18}{|l|}{ Closing session } \\
\hline \multicolumn{18}{|l|}{ Plenary speaker Finn Kydland } \\
\hline \multicolumn{18}{|c|}{ Plenary speaker Hans-Jürgen Zimmermann } \\
\hline \multicolumn{18}{|c|}{ Plenary speaker Ralph E. Gomory } \\
\hline \multicolumn{18}{|c|}{ Keynote speaker Ignacio Grossmann } \\
\hline \multicolumn{18}{|l|}{ Tutorial speaker Erhan Erkut } \\
\hline \multicolumn{18}{|l|}{ Keynote speaker Ceyda Oguz } \\
\hline \multicolumn{18}{|l|}{ Tutorial speaker Kenneth Sörensen } \\
\hline \multicolumn{18}{|l|}{ Tutorial speaker Anita Schöbel } \\
\hline \multicolumn{18}{|l|}{ Tutorial speaker Guy Desaulniers } \\
\hline \multicolumn{18}{|l|}{ Keynote speaker Bjorn Jorgensen } \\
\hline \multicolumn{18}{|l|}{ Tutorial speaker Jitka Dupacova } \\
\hline \multicolumn{18}{|l|}{ Keynote speaker Boris Polyak } \\
\hline \multicolumn{18}{|l|}{ Keynote speaker Matteo Fischetti } \\
\hline \multicolumn{18}{|l|}{ Keynote speaker Jonathan Caulkins } \\
\hline \multicolumn{18}{|l|}{ Tutorial speaker Karla Hoffman } \\
\hline \multicolumn{18}{|c|}{ Actuarial Sciences and Stochastic Calculus } \\
\hline \multicolumn{18}{|l|}{$\begin{array}{l}\text { Advanced Inventory Control } \\
\text { and Pricing Strategies }\end{array}$} \\
\hline \multicolumn{18}{|c|}{$\begin{array}{l}\text { Analytic Hierarchy Process, Analytic } \\
\text { Network Process }\end{array}$} \\
\hline \multicolumn{18}{|c|}{ Applications of Location Analysis } \\
\hline \multicolumn{18}{|l|}{ Arc Routing } \\
\hline \multicolumn{18}{|c|}{ Boolean and Pseudo-Boolean Optimization } \\
\hline \multicolumn{18}{|c|}{ Business Excellence in Logistics } \\
\hline Combinatorial Optimization & & & & & & & & & & & & & & & & & \\
\hline Commodities and Financial Moc & & & & & & & & & & & & & & & & & \\
\hline $\begin{array}{l}\text { Computational Biology, } \\
\text { Bioinformatics and Medicine }\end{array}$ & & & & & & & & & & & & & & & & & \\
\hline Computational Statistics & & & & & & & & & & & & & & & & & \\
\hline Container Terminal Operations & & & & & & & & & & & & & & & & & \\
\hline Continuous Location & & & & & & & & & & & & & & & & & \\
\hline
\end{tabular}




\begin{tabular}{|c|c|c|c|c|c|c|c|c|c|c|c|c|c|c|c|c|c|}
\hline & $\begin{array}{c}8 \\
\ddot{0} \\
0 \\
1 \\
0 \\
0 \\
\ddot{0} \\
-\end{array}$ & 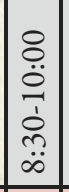 & 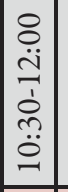 & 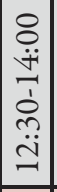 & 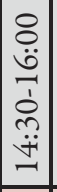 & 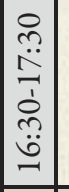 & $\begin{array}{c}0 \\
0 \\
\ddot{0} \\
1 \\
0 \\
\stackrel{n}{0} \\
\ddot{\infty}\end{array}$ & 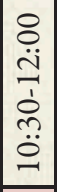 & 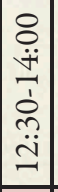 & 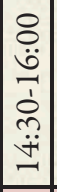 & 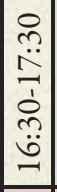 & \begin{tabular}{|c|}
0 \\
0 \\
$\dot{0}$ \\
0 \\
0 \\
0 \\
$\ddot{\infty}$ \\
$\ddot{\infty}$ \\
\end{tabular} & 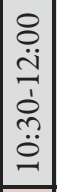 & 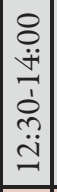 & 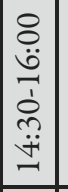 & 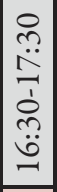 & 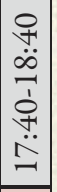 \\
\hline Stream & SA & MA & $\mathrm{MB}$ & $\mathrm{MC}$ & $\mathrm{MD}$ & ME & TA & $\mathrm{TB}$ & $\mathrm{TC}$ & $\mathrm{TD}$ & $\mathrm{TE}$ & WA & WB & WC & WD & WE & WF \\
\hline \multicolumn{18}{|l|}{$\begin{array}{l}\text { Control Theory \& System Dynamics } \\
\text { (contributed) }\end{array}$} \\
\hline \multicolumn{18}{|l|}{ Convex Optimization } \\
\hline \multicolumn{18}{|l|}{ Cooperative Game Theory } \\
\hline \multicolumn{18}{|l|}{ Cutting and Packing } \\
\hline \multicolumn{18}{|l|}{ Data Confidentiality } \\
\hline \multicolumn{18}{|l|}{ Data Mining and Decision Making } \\
\hline \multicolumn{18}{|l|}{ Data Mining in Early Warning Systems } \\
\hline \multicolumn{18}{|l|}{ Data Mining in the Financial Sector } \\
\hline \multicolumn{18}{|l|}{$\begin{array}{l}\text { Data Mining, Knowledge Discovery } \\
\text { and Artificial Intelligence }\end{array}$} \\
\hline \multicolumn{18}{|l|}{ DEA and Performance Measurement } \\
\hline \multicolumn{18}{|l|}{$\begin{array}{l}\text { DEA and Performance } \\
\text { Measurement (contributed) }\end{array}$} \\
\hline \multicolumn{18}{|l|}{$\begin{array}{l}\text { Decision Making Modeling and Risk } \\
\text { Assessment in the Financial Sector }\end{array}$} \\
\hline \multicolumn{18}{|l|}{ Decision Processes } \\
\hline \multicolumn{18}{|l|}{ Decision Support Systems } \\
\hline \multicolumn{18}{|l|}{$\begin{array}{l}\text { Demand and Supply in Consumer } \\
\text { Goods and Retailing }\end{array}$} \\
\hline \multicolumn{18}{|l|}{$\begin{array}{l}\text { Discrete Optimization, } \\
\text { Geometry \& Graphs (contributed) }\end{array}$} \\
\hline \multicolumn{18}{|l|}{ Dynamic Programming } \\
\hline \multicolumn{18}{|l|}{ Dynamical Systems and Game Theory } \\
\hline \multicolumn{18}{|l|}{$\begin{array}{l}\text { Dynamical Systems and } \\
\text { Mathematical Modelling in OR }\end{array}$} \\
\hline \multicolumn{18}{|l|}{$\begin{array}{l}\text { Emerging Applications in Finance } \\
\text { and Logistics }\end{array}$} \\
\hline \multicolumn{18}{|c|}{$\begin{array}{l}\text { Emerging Applications of Fat Tail Models in } \\
\text { Financial Modeling and Engineering }\end{array}$} \\
\hline \multicolumn{18}{|c|}{$\begin{array}{l}\text { Emerging Aspects of Production Planning } \\
\text { in Continuous Process Industries: Theory, } \\
\text { Optimization, and Practice }\end{array}$} \\
\hline \multicolumn{18}{|c|}{ Emissions Trading and Energy } \\
\hline \multicolumn{18}{|l|}{ Energy, Environment and Climate 1} \\
\hline Energy, Environment and Climate 2 & & & & & & & & & & & & & & & & & \\
\hline
\end{tabular}




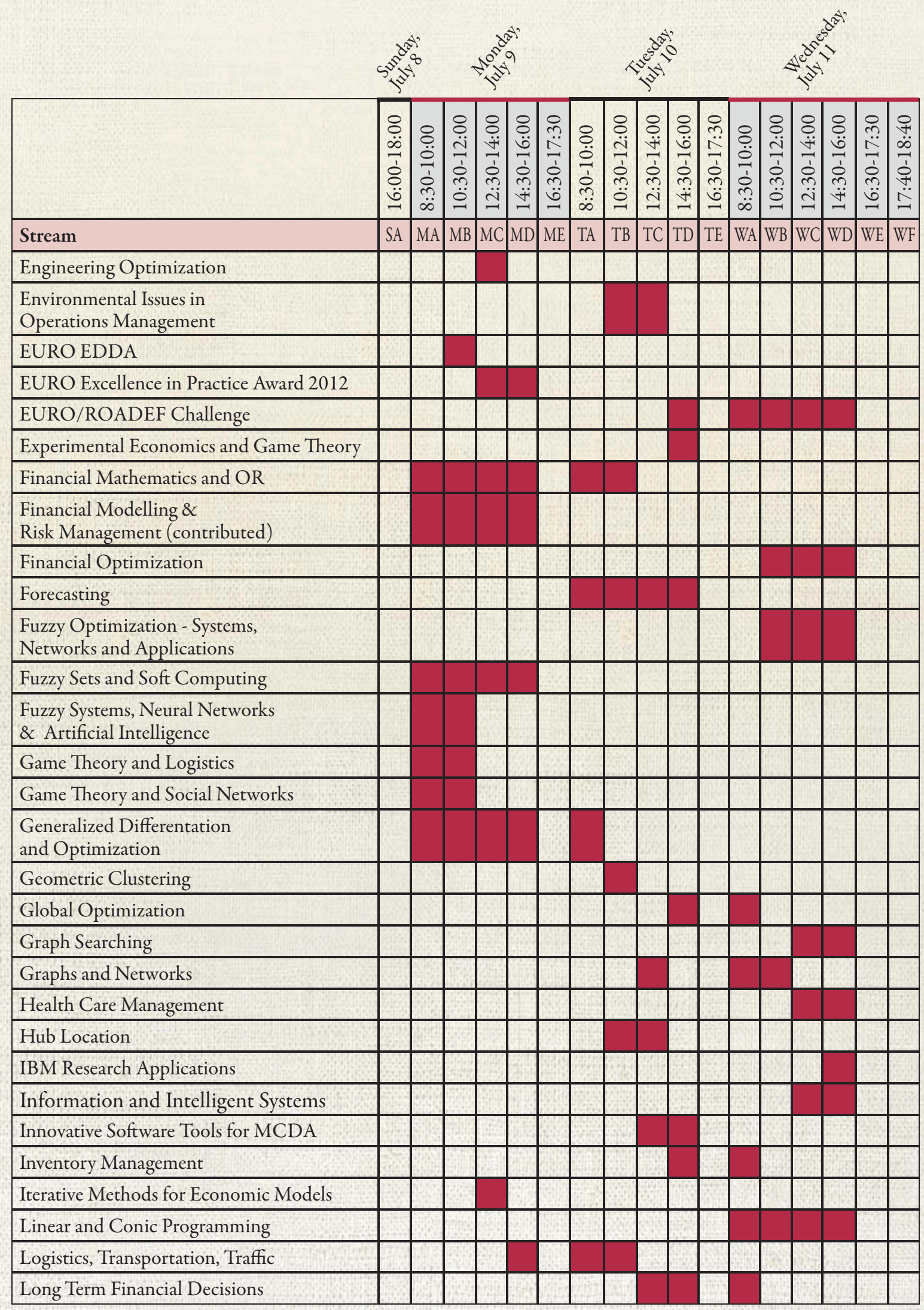




\begin{tabular}{|c|c|c|c|c|c|c|c|c|c|c|c|c|c|c|c|c|c|}
\hline & $\begin{array}{c}8 \\
\ddot{0} \\
0 \\
1 \\
0 \\
0 \\
\ddot{0} \\
-\end{array}$ & 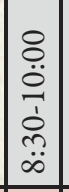 & 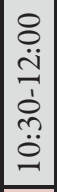 & 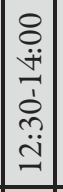 & 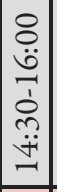 & 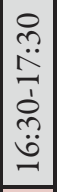 & $\begin{array}{c}0 \\
0 \\
\ddot{0} \\
1 \\
0 \\
\ddot{\infty} \\
\infty\end{array}$ & 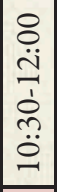 & 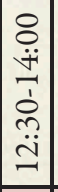 & 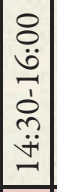 & 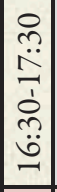 & \begin{tabular}{|c|}
0 \\
0 \\
$\dot{0}$ \\
0 \\
0 \\
0 \\
$\ddot{\infty}$ \\
$\ddot{\infty}$ \\
\end{tabular} & 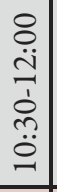 & 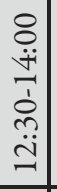 & 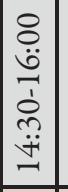 & 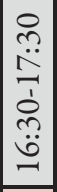 & 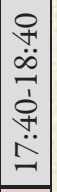 \\
\hline Stream & SA & MA & $\mathrm{MB}$ & $\mathrm{MC}$ & $\mathrm{MD}$ & ME & $\mathrm{TA}$ & $\mathrm{TB}$ & $\mathrm{TC}$ & $\mathrm{TD}$ & $\mathrm{TE}$ & WA & WB & $\mathrm{WC}$ & WD & WE & WF \\
\hline \multicolumn{18}{|l|}{$\begin{array}{l}\text { Long Term Planning in Energy, } \\
\text { Environment and Climate }\end{array}$} \\
\hline \multicolumn{18}{|l|}{ Lot-sizing and Related Topics } \\
\hline \multicolumn{18}{|l|}{ Machine Learning and its Applications } \\
\hline \multicolumn{18}{|l|}{ Manufacturing and Warehousing } \\
\hline \multicolumn{18}{|l|}{ Maritime Transportation } \\
\hline \multicolumn{18}{|l|}{$\begin{array}{l}\text { Mathematical Models in } \\
\text { Macro- and Microeconomics }\end{array}$} \\
\hline \multicolumn{18}{|l|}{ Mathematical Programming } \\
\hline \multicolumn{18}{|l|}{ Matheuristics } \\
\hline \multicolumn{18}{|c|}{ MCDA: New Approaches and Applications } \\
\hline \multicolumn{18}{|c|}{ Metaheuristics } \\
\hline \multicolumn{18}{|l|}{ Methodology of Societal Complexity } \\
\hline \multicolumn{18}{|l|}{ Mixed-Integer Non-Linear Programming } \\
\hline \multicolumn{18}{|l|}{ Models of Embodied Cognition } \\
\hline \multicolumn{18}{|l|}{$\begin{array}{l}\text { Multi-Criteria Decision Making and } \\
\text { Environmental Management }\end{array}$} \\
\hline \multicolumn{18}{|l|}{ Multiobjective Optimization } \\
\hline \multicolumn{18}{|l|}{ Network and Discrete Location } \\
\hline \multicolumn{18}{|l|}{ Network Optimization } \\
\hline \multicolumn{18}{|l|}{ New Trends in Vehicle Routing } \\
\hline \multicolumn{18}{|l|}{$\begin{array}{l}\text { Nonconvex Programming: } \\
\text { Local and Global Approaches }\end{array}$} \\
\hline \multicolumn{18}{|l|}{ Nonlinear Programming } \\
\hline \multicolumn{18}{|l|}{ Nonsmooth Optimization } \\
\hline \multicolumn{18}{|l|}{ Numerical Methods in Finance } \\
\hline \multicolumn{18}{|l|}{ Occupational Heath \& Wellbeing } \\
\hline \multicolumn{18}{|l|}{$\begin{array}{l}\text { Operational Research and Quantitative } \\
\text { Models in Banking }\end{array}$} \\
\hline Operations/Marketing Interface & & & & & & & & & & & & & & & & & \\
\hline Optimal Control & & & & & & & & & & & & & & & & & \\
\hline Optimization and Data Mining & & & & & & & & & & & & & & & & & \\
\hline Optimization for Sustainable Develop & & & & & & & & & & & & & & & & & \\
\hline Optimization in Public Transport & & & & & & & & & & & & & & & & & \\
\hline OR and Environmental Management & & & & & & & & & & & & & & & & & \\
\hline
\end{tabular}




\begin{tabular}{|c|c|c|c|c|c|c|c|c|c|c|c|c|c|c|c|c|c|}
\hline & $\begin{array}{l}8 \\
\ddot{0} \\
\ddot{0} \\
\overrightarrow{0} \\
\ddot{0} \\
\stackrel{0}{0}\end{array}$ & $\begin{array}{l}8 \\
0 \\
0 \\
0 \\
0 \\
0 \\
0 \\
0\end{array}$ & 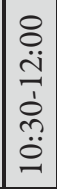 & $\mid \begin{array}{c}\delta \\
\dot{+} \\
\dot{ت} \\
\dot{0} \\
\ddot{ت} \\
\ddot{ت}\end{array}$ & 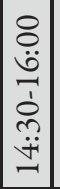 & 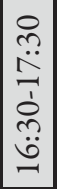 & $\begin{array}{l}8 \\
0 \\
\ddot{0} \\
1 \\
0 \\
0 \\
0 \\
0\end{array}$ & 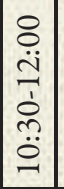 & 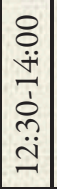 & 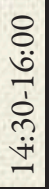 & 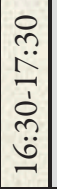 & $\begin{array}{c}8 \\
0 \\
\ddot{0} \\
1 \\
0 \\
\ddot{\infty}\end{array}$ & 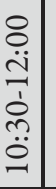 & $\begin{array}{l}8 \\
\dot{ \pm} \\
\overline{0} \\
\ddot{\Xi} \\
\ddot{\Xi}\end{array}$ & 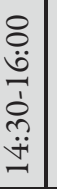 & 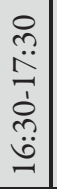 & 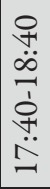 \\
\hline Stream & SA & MA & MB & $\mathrm{MC}$ & MD & ME & $\mathrm{TA}$ & $\mathrm{TB}$ & $\mathrm{TC}$ & $\mathrm{TD}$ & $\mathrm{TE}$ & WA & WB & WC & WD & WE & WF \\
\hline \multicolumn{18}{|l|}{ OR and Ethics } \\
\hline \multicolumn{18}{|l|}{ OR and Real Implementations } \\
\hline \multicolumn{18}{|l|}{ OR and the Arts } \\
\hline \multicolumn{18}{|l|}{ OR Applications in Industry } \\
\hline \multicolumn{18}{|l|}{$\begin{array}{l}\text { OR Applications in } \\
\text { the Automotive Industry }\end{array}$} \\
\hline \multicolumn{18}{|l|}{$\begin{array}{l}\text { OR for Development and } \\
\text { Developing Countries }\end{array}$} \\
\hline \multicolumn{18}{|l|}{ OR for Sustainable Development } \\
\hline \multicolumn{18}{|l|}{ OR in Agriculture, Forestry and Fisheries } \\
\hline \multicolumn{18}{|l|}{ OR in Health \& Life Sciences (contributed) } \\
\hline \multicolumn{18}{|c|}{ OR in Human Resources } \\
\hline \multicolumn{18}{|l|}{$\begin{array}{l}\text { OR in Industry and Software } \\
\text { for OR (contributed) }\end{array}$} \\
\hline \multicolumn{18}{|l|}{$\begin{array}{l}\text { OR in Military, Safety and } \\
\text { Security Applications }\end{array}$} \\
\hline \multicolumn{18}{|l|}{ OR in Quality Management } \\
\hline \multicolumn{18}{|l|}{ OR in Sports } \\
\hline \multicolumn{18}{|l|}{ OR in the Oil and Gas Sectors } \\
\hline \multicolumn{18}{|l|}{ OR in Water Management } \\
\hline \multicolumn{18}{|l|}{ Pioneers in Operations Research } \\
\hline \multicolumn{18}{|l|}{ Preference Learning } \\
\hline \multicolumn{18}{|l|}{$\begin{array}{l}\text { Production and the Link } \\
\text { with Supply Chains }\end{array}$} \\
\hline \multicolumn{18}{|l|}{$\begin{array}{l}\text { Production Management } \& \text { Supply Chain } \\
\text { Management (contributed) }\end{array}$} \\
\hline \multicolumn{18}{|l|}{ Project Management and Scheduling } \\
\hline \multicolumn{18}{|l|}{$\begin{array}{l}\text { Quantitative Approaches in Managerial } \\
\text { and Financial Accounting }\end{array}$} \\
\hline \multicolumn{18}{|l|}{$\begin{array}{l}\text { Quantitative Models for Performance } \\
\text { and Dependability }\end{array}$} \\
\hline \multicolumn{18}{|l|}{ Realistic Production Scheduling } \\
\hline \multicolumn{18}{|l|}{ Recent Advances in Earthquake Studies } \\
\hline Revenue Management & & & & & & & & & & & & & & & & & \\
\hline Scheduling & & & & & & & & & & & & & & & & & \\
\hline Scheduling under Resource Constraints & & & & & & & & & & & & & & & & & \\
\hline
\end{tabular}




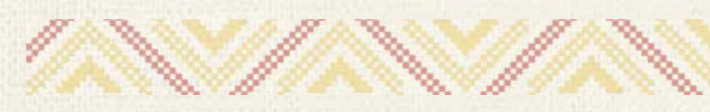

\begin{tabular}{|c|c|c|c|c|c|c|c|c|c|c|c|c|c|c|c|c|}
\hline & 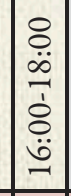 & $\begin{array}{c}0 \\
8 \\
0 \\
\dot{0} \\
1 \\
0 \\
0 \\
0 \\
\end{array}$ & 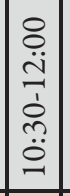 & 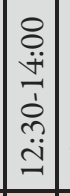 & 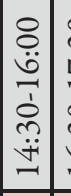 & 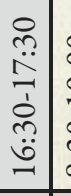 & $\begin{array}{l}8 \\
o \\
\ddot{0} \\
1 \\
0 \\
0 \\
\infty \\
\end{array}$ & 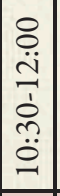 & 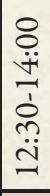 & $\begin{array}{l}8 \\
\dot{0} \\
\dot{1} \\
\dot{0} \\
0 \\
\dot{+} \\
-\end{array}$ & 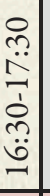 & $\begin{array}{l}8 \\
\vdots \\
\ddot{0} \\
1 \\
0 \\
0 \\
0\end{array}$ & 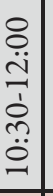 & 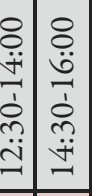 & 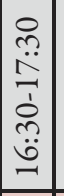 & 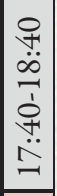 \\
\hline Stream & $S A$ & MA & MB & $\mathrm{MC}$ & MD 1 & ME 1 & $\mathrm{TA}$ & $\mathrm{TB}$ & TC & TD & $\mathrm{TE}$ & $\mathrm{WA}$ & WB & \begin{tabular}{l|l|}
$\mathrm{WC}$ & $\mathrm{WD}$
\end{tabular} & WE & WF \\
\hline SD Modelling in Sustainable Development & & & & & & & & & & & & & & & & \\
\hline Semi-Infinite Optimization & & & & & & & & & & & & & & & & \\
\hline Simulation & & & & & & & & & & & & & & & & \\
\hline Simulation Based Decision Support & & & & & & & & & & & & & & & & \\
\hline $\begin{array}{l}\text { Simulation in Management Accounting } \\
\text { and Management Control }\end{array}$ & & & & & & & & & & & & & & & & \\
\hline Simulation Methods in Finance & & & & & & & & & & & & & & & & \\
\hline Soft OR and Problem Structuring Methods & & & & & & & & & & & & & & & & \\
\hline Software for OR/MS & & & & & & & & & & & & & & & & \\
\hline $\begin{array}{l}\text { Stochastic Modeling and Simulation in } \\
\text { Engineering, Management and Science }\end{array}$ & & & & & & & & & & & & & & & & \\
\hline Stochastic Modelling in Logistical Networks & & & & & & & & & & & & & & & & \\
\hline Stochastic Programming & & & & & & & & & & & & & & & & \\
\hline Structured Optimization and Applications & & & & & & & & & & & & & & & & \\
\hline Supply Chain Management & & & & & & & & & & & & & & & & \\
\hline Supply Chain Planning & & & & & & & & & & & & & & & & \\
\hline $\begin{array}{l}\text { Sustainable Living: Cognitive, Social, } \\
\text { Economical, Ecological and World View }\end{array}$ & & & & & & & & & & & & & & & & \\
\hline Sustainable Transport Planning & & & & & & & & & & & & & & & & \\
\hline System Dynamics Modeling and Simulation & & & & & & & & & & & & & & & & \\
\hline Timetabling and Rostering & & & & & & & & & & & & & & & & \\
\hline Transportation and Logistics & & & & & & & & & & & & & & & & \\
\hline Transportation Planning & & & & & & & & & & & & & & & & \\
\hline $\begin{array}{l}\text { Uncertainty and Perturbations in } \\
\text { Optimization and in Environmental } \\
\text { and Energy Modelling }\end{array}$ & & & & & & & & & & & & & & & & \\
\hline Variable Neighborhood Search & & & & & & & & & & & & & & & & \\
\hline $\begin{array}{l}\text { Variational Inequalities and } \\
\text { Bi-Level Problems }\end{array}$ & & & & & & & & & & & & & & & & \\
\hline Vector and Set-Valued Optimization & & & & & & & & & & & & & & & & \\
\hline Vehicle Routing and Logistics Optimization & & & & & & & & & & & & & & & & \\
\hline $\begin{array}{l}\text { Young People for System Theory, } \\
\text { Optimization and Education }\end{array}$ & & & & & & & & & & & & & & & & \\
\hline
\end{tabular}

